\title{
inf \\ Comparative Panel File: \\ Household Panel Surveys from Seven Countries. \\ Manual for CPF v.1.0
}

Konrad Turek

Matthijs Kalmijn

Thomas Leopold

www.cpfdata.com

Netherlands Interdisciplinary Demographic Institute

The Hague, Netherlands

2020 


\begin{abstract}
The Comparative Panel File (CPF) harmonises the world's largest and longest-running household panel surveys from seven countries: Australia (HILDA), Germany (SOEP), Great Britain (BHPS and UKHLS), South Korea (KLIPS), Russia (RLMS), Switzerland (SHP), and the United States (PSID). The project aims to support the social science community in the analysis of comparative life course data. The CPF is not a data product but an open-source code that integrates individual and household panel data from all seven surveys into a harmonised three-level data structure. In this manual, we present the design and content of the CPF, explain the logic of the project, workflow and technical details. We also describe the CPF's open-science platform.
\end{abstract}

\title{
CPF team
}

\section{Thomas Leopold}

University of Cologne

Matthijs Kalmijn

Netherlands Interdisciplinary Demographic Institute

Konrad Turek

Netherlands Interdisciplinary Demographic Institute

\section{Citation:}

Turek K., Kalmijn M., Leopold T. (2020). Comparative Panel File: Household Panel Surveys from Seven Countries. Manual for CPF v.1.0. The Hague: Netherlands Interdisciplinary Demographic Institute 


\section{Contents}

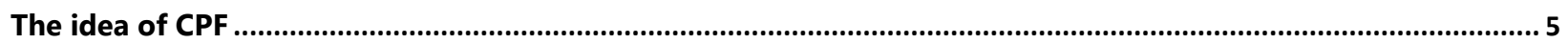

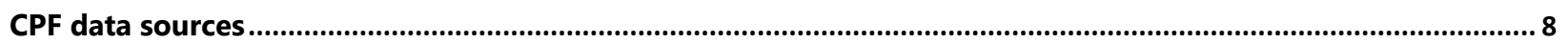

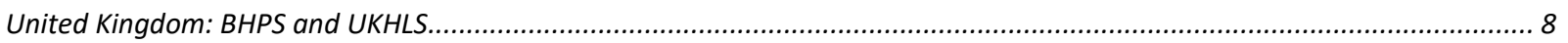

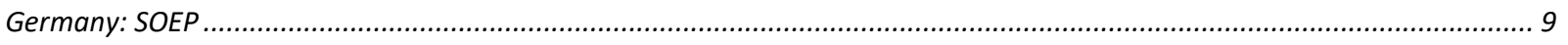

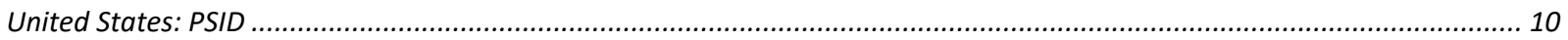

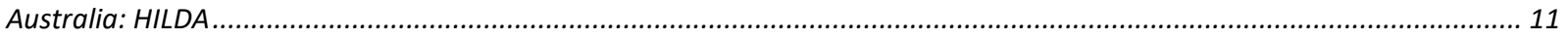

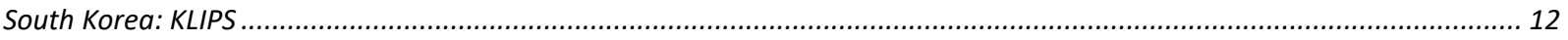

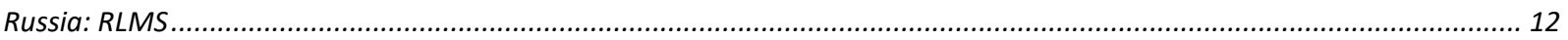

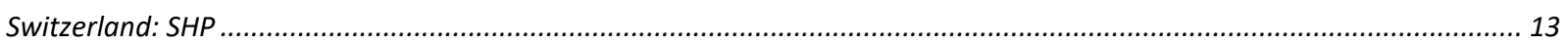

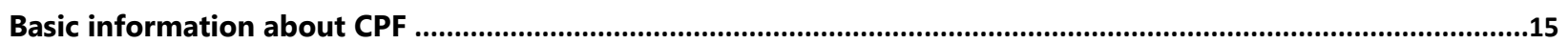

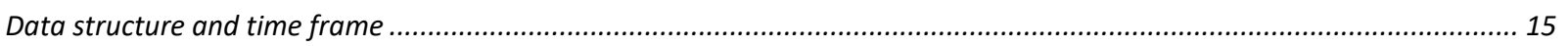

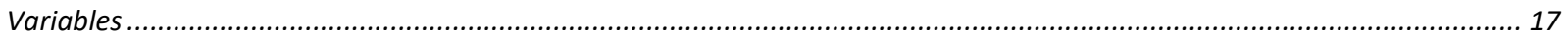

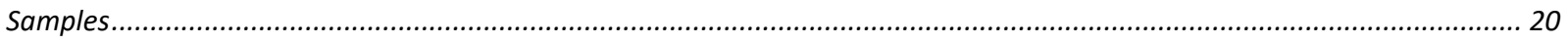

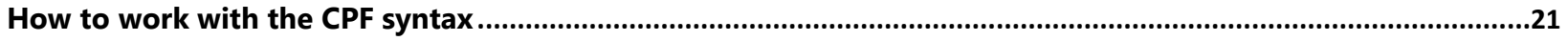

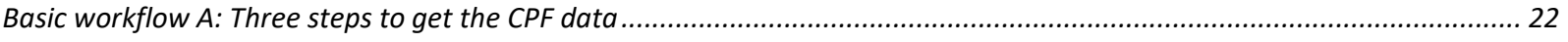

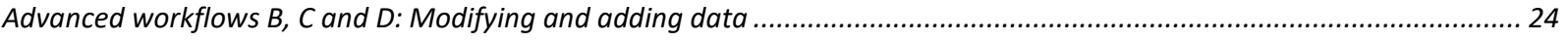

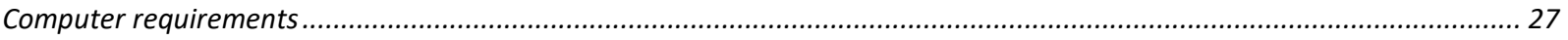

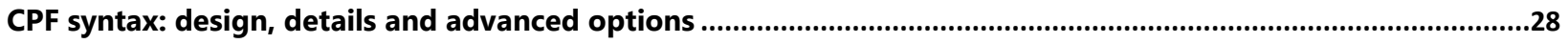

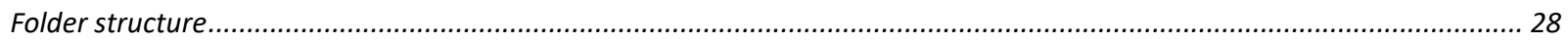

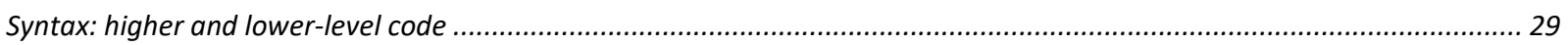

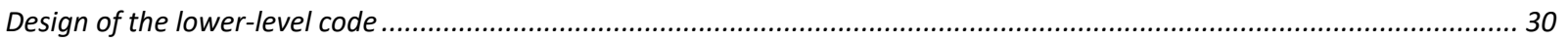

Obtaining the original data

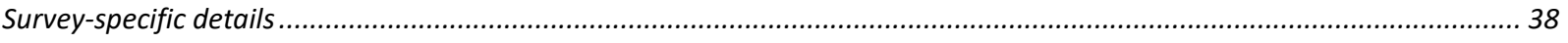

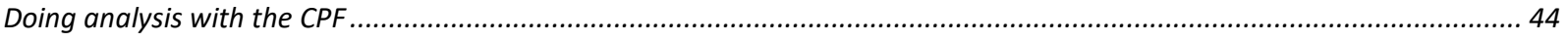

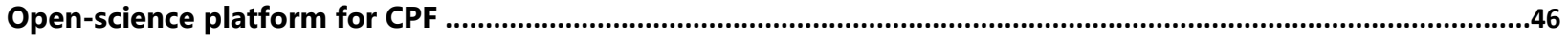

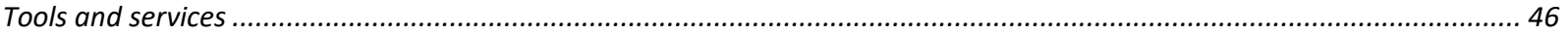

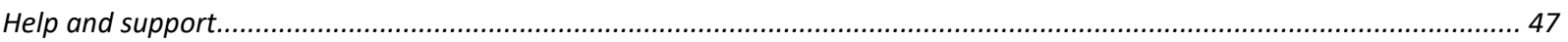

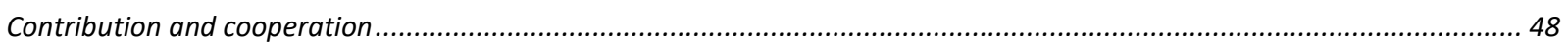

References 


\section{List of symbols and abbreviations}

\section{Symbols}

Folder directory:

$\mathrm{D}: \backslash \mathrm{CPF} \backslash 11$ _CPF_in_syntax

Syntax do-file:

1_Folder_setup

Data file:

CPF_v1.0.dta

Variable:

country

Syntax code:

global your_dir "D:\CPF" //<--inster your directory

\section{Abbreviations}

CPF

Comparative Panel File

CNEF

Cross-National Equivalent File

BHPS

British Household Panel Survey

HILDA

Household, Income and Labor Dynamics in Australia Survey

KLIPS

Korean Labor and Income Panel Study

PSID

Panel Study of Income Dynamics

RLMS

Russian Longitudinal Monitoring Survey

SHP

Swiss Household Panel

SOEP

German Socio-Economic Panel

UKHLS

Understanding Society - The UK Household Longitudinal Study

AUS

Australia

GER

Germany

KOR

South Korea

RUS

Russia

SWT

Switzerland

UK

United Kingdom

US

United States 


\section{The idea of CPF}

Comparative Panel File (CPF) is as an ongoing, open science project to harmonise the world's largest and longest-running household panel surveys from seven countries. The project aims to support the social science community in the analysis of comparative life course data. By harmonising individual repeated data covering long periods and several general population surveys, researchers can analyse both time trends and country differences. The CPF is not a data product, but an open-source Stata code that integrates individual and household panel data into a harmonised three-level data structure. he opensource character of the code allows for developing and extending areas of application. Currently, CPF includes seven studies:

- Australia (The Household, Income and Labor Dynamics in Australia Survey, HILDA),

- Germany (The German Socio-Economic Panel, SOEP),

- the United Kingdom (The British Household Panel Survey, BHPS, and Understanding Society The UK Household Longitudinal Study, UKHLS),

- South Korea (The Korean Labor and Income Panel Study, KLIPS),

- Russia (The Russian Longitudinal Monitoring Survey, RLMS),

- Switzerland (The Swiss Household Panel, SHP), and

- the United States (The Panel Study of Income Dynamics, PSID).

The idea originated in 2019 in the context of the project "Critical Life Events and the Dynamics of Inequality: Risk, Vulnerability, and Cumulative Disadvantage" (CRITEVENTS). CRITEVENTS is funded by NORFACE through the transnational research programme "Dynamics of Inequality Across the Life-Course: Structures and Processes (DIAL)." ${ }^{1}$ The initial motivation to harmonise data from national panel surveys was the fact that the CNEF release did not include measures for job loss and unemployment. Instead of harmonising only these variables, we decided to extend the approach pioneered by CNEF to a larger set of key variables of social science research and make the result available to the broader scientific community. Currently, CPF is managed and developed by Konrad Turek and Matthijs Kalmijn at the Netherlands Interdisciplinary Demographic Institute (NIDI-KNAW) and Thomas Leopold at the University

\footnotetext{
${ }^{1}$ This article forms part of the CRITEVENTS project. The CRITEVENTS project is financially supported by the NORFACE Joint Research Programme on the Dynamics of Inequality Across the Life-course, which is co-funded by the European Commission through Horizon 2020 under grant agreement No 724363.
} 
of Cologne. ${ }^{2}$ The CPF code and entire open-science platform were designed and prepared by Konrad Turek and will be continuously developed and improved by the CPF team and the community of users.

The CNEF is a long-running and well-established project which harmonises international longitudinal surveys of households (Burkhauser, Butrica, Daly, \& Lillard, 2001; Frick, Jenkins, Lillard, Lipps, \& Wooden, 2007). It has been developed since 1990 under the lead of researchers from Cornell University. Over the years, the project was managed primarily by Dean R. Lillard and administered by Cornell University and Ohio State University. ${ }^{3}$ Initially, in 1991, the dataset harmonised only a limited set of variables for two countries, the US and Germany. ${ }^{4}$ Over the years, the project expanded by adding countries, such as the UK and Canada ${ }^{5}$ in 1999, Australia and Switzerland in 2007, and Russia and Japan in later years. The set of topics and variables has been gradually extended, but the main focus remains on income and earnings. CNEF has been used primarily in income-related research in economics (Allanson, 2011; Büchel \& Frick, 2004; Chen, 2009), sociology (DiPrete \& McManus, 1996; Ehlert, 2013; McCall \& Percheski, 2010; Musick, Bea, \& Gonalons-Pons, 2020), or demography (Cooke, Boyle, Couch, \& Feijten, 2009), and less often in research on other topics, such as life satisfaction (Cho \& Lee, 2013), and self-employment (McManus, 2003).

The CPF project makes several important steps forward. First and foremost, CPF has a broad focus, including information about education, family and marital relationship, labour market status, subjective wellbeing and work satisfaction, social origin, and socio-economic status, in addition to the classic economic variables also present in CNEF. For several of these variables, CPF also offers more detail; for example, it allows distinguishing between unemployed, retired, self-employed or entrepreneurs. Second, CPF is open and flexible, thereby facilitating a genuine bottom-up approach. CPF fully supports modifications in harmonised variables or adding new variables from the source database, depending on researchers' needs. Our code is available in full and for all selected countries. It also facilitates work with single surveys, as it instructs how to go from a large set of raw files to an integrated and ready for analysis

\footnotetext{
2 The CPF team would like to thank to the colleagues who supported development of the first version of CPF, in particular (in alphabetical order) Eldad Davidov, Dina Maskileyson, Aleja Rodríguez, Katya Sytkina, and Gordey Yastrebov.

${ }^{3}$ The CNEF involved a cooperation with national source data administrators, an international group of researchers from US, Germany, UK, Switzerland, Australia, Korea, Russia and Canada. CNEF was funded by several institutions, including the US National Institute on Aging, the German Institute for Economic Research, and Cornell University.

4 The CNEF was built on the model implemented in the Luxembourg Income Study (LIS), which harmonizes micro-level household surveys data from over 25 countries (Burkhauser et al., 2001; Frick et al., 2007). LIS was limited by the crosssectional character of the data, and difficulties in accessing the data due to confidentiality issues. CNEF aimed at harmonizing more accessible panel data and including a broader range of research topics than LIS.

${ }^{5}$ The Canadian Survey of Labour and Income Dynamics (SLID) is discontinued.
} 
panel data set (for some surveys, e.g., PSID, this is a complex process). In contrast, CNEF is a data product that offers a set of separate data files, but only parts of the code are available. Third, CPF does not depend on direct government funding, which greatly facilitates the speed and direction of its further development. New waves can be added as soon as these are released by the national data centres. CNEF files are released differently by country, and most do not cover recent waves. Fourth, procedures to obtain and use the data are streamlined and greatly simplified. The only administrative step needed is obtaining permission to use the national data from each of the seven national data centres. This may be some work, but when permission is obtained, the openly available code can be run, and the CPF is readily available on the user's computer. CNEF requires an additional application for accessing some surveys, separate CNEF files are provided partly online and partly on a CD sent by mail, and they still have to be integrated.

In sum, we build on the approach pioneered by CNEF and other cross-national data harmonisation projects (Dubrow \& Tomescu-Dubrow, 2015), but overcome the main limitations for users who require a broader set of variables and more flexibility and control over the data management process.

The CPF provides free and full access to a code that generates a comparative dataset based on these household panel surveys. The code and complete documentation are available at www.cpfdata.com. After securing access to the national panel surveys, users can run our code which combines datasets and waves within a country, constructs harmonised variables and merges these into one data set for all countries and all waves. Users can either follow the default workflow and run the code unchanged or modify and improve it for their use (e.g., select countries, add new waves, add new or modify existing variables). The file is organised in a long format which contains one record for each person in each wave. The merged file of CPF version 1.0 contains around 2.7 million observations from almost 360 thousand individuals observed for an average of 7.5 waves (up to 40 waves).

The CPF is organised as an open science platform that integrates several tools that support open collaboration, management, documenting and sharing all materials. The main elements of the platform are the website (central platform) with forum (general communication), GitHub code repository (code development), and Open Science Framework (general management of scientific research). User's improvements and suggestions will be recorded, incorporated and shared using open online tools to allow continuous development and regular updates to the official versions of the code. 


\section{CPF data sources}

Data for the CPF come from household panel studies - general population repeated surveys with household as the primary sampling unit. They regularly (mostly yearly) interview all or selected adult members of sampled households over a period of years and collect information about the entire household and its members (Rose, 1995). Version 1.0 of the CPF combines seven most established and longest-running household panel studies globally. All studies are representative of the population of households. As ongoing panel studies, they continuously renew their samples by including new household members (e.g. grown-up children, newly married partners), following new independent household established by respondents (e.g. children leaving parents' homes), by refreshments (e.g. including a new set of households), or by extensions (e.g. including a new type of households, such as new migrant families). Many panels included systematic oversamples of subgroups; these are included in the CPF but identifiable with country-specific variables.

\section{United Kingdom: BHPS and UKHLS}

The UK's CPF sample consists of two studies: The British Household Panel Survey (BHPS) covering years 1991-2008 (18 waves) and Understanding Society: The UK Household Longitudinal Study (UKHLS) from 2009 onwards (Buck \& McFall, 2012; Platt, Knies, Luthra, Nandi, \& Benzeval, 2020). BHPS began in 1991 as a multi-purpose panel survey for social and economic research. It was run on a yearly basis with the same individuals re-interviewed each successive year. The first wave of BHPS consisted of ca. 5,500 households and 10,300 individuals drawn from 250 areas of Great Britain. In following years additional samples were added, including 1,500 households in Scotland and 1,500 households in Wales (1999), and 2,000 households in Northern Ireland (2001).

Since 2009, BHPS has been integrated into UKHLS. With a target sample size of 40,000 households in wave 1, UKHLS became the largest nationally representative household panel study worldwide. Young people aged 10-15 complete a youth questionnaire. Respondents aged 16 and over complete the adult survey and continue to be interviewed when they leave their original households. Data continue to be collected every, yet the fieldwork is extended to around 2,5 year for each wave (e.g. the $1^{\text {st }}$ wave of UKHLS covers years 2009-2011, the $2^{\text {nd }}$ covers years 2010-2012). Both BHPS and UKHLS have been developed and carried out by the Institute for Social and Economic Research at the University of Essex.

For more information, see: 
- BHPS: $\underline{w w w . i s e r . e s s e x . a c . u k / b h p s}$,

- UKLHS: www.understandingsociety.ac.uk

- Data are available via the UK Data Service after granting access: www.ukdataservice.ac.uk.

For citing, please follow instructions of UKHLS, e.g.:

University of Essex, Institute for Social and Economic Research, NatCen Social Research, Kantar Public. (2019). Understanding Society: Waves 1-9, 2009-2018 and Harmonised BHPS: Waves 1-18, 1991-2009. [data collection]. 12th Edition. UK Data Service. SN: 6614, http://doi.org/10.5255/UKDA-SN-6614-13.

\section{Germany: SOEP}

The German data come from the German Socio-Economic Panel (SOEP). SOEP began in 1984 as a representative longitudinal study of private households in Germany for social, behavioural, and economic research. It is designed to measure disparities in resources across individuals over the life course by reinterviewing the same household members aged 17 and older annually. Initially, SOEP included only Western Germany and since 1990 after reunification it also covers eastern parts of the country, being the only database worldwide covering such a political unification (Giesselmann et al., 2019; Goebel et al., 2019; Siegers, Belcheva, \& Silbermann, 2020).

The first wave of SOEP consisted of two samples and ca. 6,000 households from the western states of Germany: (1) with a German household head and (2) with a migrant Greek, Italian, Spanish, Turkish, or Yugoslavian household head. In 1990 the panel data was expanded to include a representative sample from East Germany. The data was further advanced by adding immigrant (1994/95 and 2013/2015) and refugee (2016 and 2017) samples. Now ca. 15,000 households and 30,000 individuals participate in the SOEP.

SOEP has been developed by Research Center 'Sonderforschungsbereich' at the Universities of Mannheim and Frankfurt/Main together with the German Institute for Economic Research (DIW Berlin). Since 1990, SOEP has been fully delegated to DIW under the umbrella of Leibniz Association with financing from the state governments and Federal Ministry of Education and Research (BMBF).

For more information, see:

- Official website: $\underline{w w w . d i w . d e / e n / s o e p}$

- SOEPcompanion: companion.soep.de 
- Additional resources (including variables-search system): paneldata.org

- Data are available via the Research Data Center SOEP after granting access: www.diw.de/en/diw 02.c.242211.en/criteria fdz soep.html

For citing, please follow instructions of SOEP, e.g.:

Socio-Economic Panel (SOEP), data for years 1984-2017, version 34, SOEP, 2019, doi: $10.5684 /$ soep.v34.

\section{United States: PSID}

The US data come from the Panel Study of Income Dynamics (PSID). It covers a period from 1968 and remains the oldest national panel survey worldwide. The study was initially created for evaluating poverty and economic wellbeing dynamics in the US. Currently, PSID aims to study the dynamics of income and poverty by interviewing only one person per family regularly.

From 1968 to 1997, the data were conducted every year. Since 1998, interviews are biennial. In 1968, ca. 5,000 families and 18,000 individuals participated in the survey. Over the decades, the PSID sample has grown though its genealogic design that allows gathering data from up to seven generations of the same family. It has collected survey information on more than 80,000 individuals in total (Johnson, McGonagle, Freedman, \& Sastry, 2018; McGonagle, Schoeni, Sastry, \& Freedman, 2012). Respondents had entered the study in three ways. Demographic inflows (birth, adoptions and marriages) brought up new members to the families. Formation of new independent households as a result of children splitting off their parents' homes provided new unit measures for PSID. Additionally, post-1968 immigrant families extended the original sample in 1997/1999. Now ca. 10000 families participate in the PSID.

To enrich data, PSID collects supplement studies. Children development (CDS) for 18 years old and younger, transition into adulthood (TAS) of those over 18, disability and use of time (DUST) for 60 and older are monitored. PSID is managed by faculty at the University of Michigan. The project's major funders are the National Science Foundation, National Institute on Aging and National Institute of Child Health and Human Development.

For more information, see:

- Official website: simba.isr.umich.edu/ 
- Data are available via the official website for registered users: simba.isr.umich.edu/Zips/ZipMain.aspx

For citing, please follow instructions of PSID, e.g.:

Panel Study of Income Dynamics, public use dataset [restricted use data, if appropriate]. Produced and distributed by the Survey Research Center, Institute for Social Research, University of Michigan, Ann Arbor, MI (year data were downloaded)

\section{Australia: HILDA}

The Australian data come from the Household, Income and Labor Dynamics (HILDA). It began in 2001 as a nationally representative longitudinal survey of Australian households. HILDA is developed to study family and labour market dynamics, economic and subjective wellbeing over the life-course (Watson \& Wooden, 2020). All working-age members of the household (over 15 years old) are re-interviewed annually. In 2001, ca. 7,682 households and 13,969 individuals participated in the survey. In 2011, 2,153 households (5,477 individuals) were additionally selected and expanded the original sample size. Since then, HILDA has followed over 17,000 Australians each year.

On a less frequent basis, further information on wealth, health care utilisation, eating habits, cognitive functioning and retirement is collected. HILDA does not conduct interviews with foreign residents in Australia, people living in outlying areas, members of non-Australian defence forces and foreign diplomatic officers. The HILDA is directed by the Melbourne Institute of Applied Economic and Social Research at the University of Melbourne and funded by the Australian Government Department of Social Services (DSS).

For more information, see:

- Official website: melbourneinstitute.unimelb.edu.au/hilda

- Data are available via the National Centre for Longitudinal Data Dataverse (Australian Government Department of Social Services): https://dataverse.ada.edu.au/dataverse/ncld

For citing, please follow instructions of HILDA, e.g.: 
Department of Social Services; Melbourne Institute of Applied Economic and Social

Research, 2017, "The Household, Income and Labour Dynamics in Australia (HILDA) Survey, GENERAL RELEASE 16 (Waves 1-16)”, doi:10.4225/87/VHRTR5, ADA Dataverse, V5

\section{South Korea: KLIPS}

The South Korean data come from the Korean Labor and Income Panel Study (KLIPS). It began in 1998 as a national longitudinal survey of households and individuals living in urban areas in South Korea. Interviews with all household members aged 15 and older are conducted annually. KLIPS monitors individuals' economic and labour activities, income and expenditures, education and job training. An original sample was developed using stratified clustering method to select districts. Out of 7 metropolitan cities and urban areas in 8 provinces, households were derived based on equal probability technique. KLIPS set out to re-interview ca. 5,000 households and 13,000 individuals every year.

Over the waves, the sample expands by adding individuals who form family ties with original panel respondents. Such sample growth enables to track demographic dynamics (e.g. marriages, births, divorces) of initial sample members. In 2009, an additional consolidated sample of 1,415 households was added to overcome the household attrition and representability issues. Since 2009, KLIPS has contained two panels within one dataset. Following families over decades allows the KLIPS data contributing to vital improvements in Korean employment policies. The project is carried out by the Korea Labor Institute and Center for Labor Statistics Research. The main funder of the study is the Ministry of Employment and Labor.

For more information, see:

- Official website: www.kli.re.kr/klips eng

- Data are available via the official website for registered users: $\underline{w w w . k l i . r e . k r / k l i p s ~ e n g}$

\section{Russia: RLMS}

The Russian data come from the Russian Longitudinal Monitoring Survey (RLMS) and cover a period from 1994. It is the longest-running panel survey of households in Eastern Europe and Asia (Gerry \& 
Papadopoulos, 2015; Kozyreva \& Sabirianova Peter, 2015). RLMS is a series of household-based nationally representative surveys which re-interview the same individuals almost every year. It aims to measure the effects of Russian reforms in economic and social sectors on individuals' welfare and health.

RLMS was initiated in 1992, and the first research phase (1992-1994) aimed to develop a sample of households that would meet statistical standards (it is not included in the CPF). The main phase of the research (RLMS-Phase II) begun in 1994 with a multi-stage probability sample covering eight regions of the Russian Federation (with 3975 households and 11290 individuals surveyed). Since then, the data has been collected annually (with two observation periods missing due to funding issues in 1997 and 1999).

The RLMS is conducted by the National Research University Higher School of Economics (HSE) in Moscow, the "Demoscope" team in Russia, and the Carolina Population Center at the University of North Carolina at Chapel Hill. Additionally, the project is co-financed by the US National Institutes of Health via a subcontract from Cornell University.

For more information, see:

- $\quad$ www.hse.ru/en/rIms

- $\quad$ www.cpc.unc.edu/projects/rlms-hse

- The data are available via the Higher School of Economics without application: www.hse.ru/en/rlms. Additionally, the data may be downloaded at the Carolina Population Center without application: $\underline{w w w . c p c . u n c . e d u / p r o j e c t s / r l m s-h s e / d a t a}$.

For citing, please follow instructions of RLMS, e.g.:

\begin{abstract}
"Russia Longitudinal Monitoring survey, RLMS-HSE”, conducted by National Research University "Higher School of Economics" and 000 "Demoscope" together with Carolina Population Center, University of North Carolina at Chapel Hill and the Institute of Sociology of the Federal Center of Theoretical and Applied Sociology of the Russian Academy of Sciences. (RLMS-HSE web sites: http://www.cpc.unc.edu/projects/rlms-hse, http://www.hse.ru/org/hse/rlms)
\end{abstract}

\title{
Switzerland: SHP
}

Swiss data come from the Swiss Household Panel (SHP) and cover a period from 1999. SHP was run as a longitudinal survey of private households based on a random representative sampling. The project aims to report the dynamics of living conditions change, income, quality of life and population representation 
in Switzerland. All household members aged 14 years and over are asked to complete an individual questionnaire every year by telephone. In 1999, ca. 5,074 households and 12,931 individuals participated in the survey.

Over a period of time, a high percentage of non-responses have accumulated in SHP. Thus, in 2004, new 2,538 households were added to the original sample to overcome the issue. In 2013 , further 4,093 households were refreshed the sample size, although different measures were implemented to return those who refused to participate.

The SHP has been developed and funded by the Swiss National Science Foundation. The project was carried out by the Swiss Federal Statistical Office and the University of Neuchâtel. Since 2008, SHP has been integrated into the Swiss Centre of Expertise in the Social Sciences (FORS) and hosted by the University of Lausanne.

For more information, see:

- Official website: https://forscenter.ch/projects/swiss-household-panel/

- Data are available via FORSbase for registered users: https://forscenter.ch/projects/swisshousehold-panel/data/

For citing, please follow instructions of SHP, e.g. all publications must carry the following:

"This study has been realised using data collected by the Swiss Household Panel (SHP), which is based at the Swiss Centre of Expertise in the Social Sciences FORS. The project is supported by the Swiss National Science Foundation”. 


\section{Basic information about CPF}

\section{Data structure and time frame}

CPF is a comparative panel dataset with a hierarchical structure of data. The structure has three levels (Figure 1): repeated individual observations from multiple waves (level-1) are clustered within individuals (level-2), and individuals are clustered within countries (level-3).

Figure 1. CPF data structure

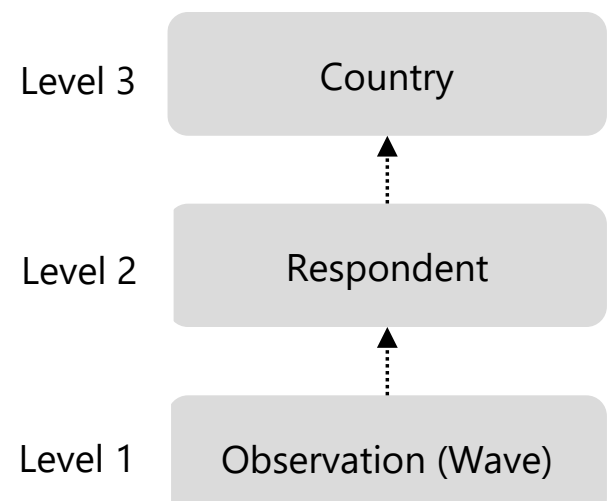

The CPF version 1.0 covers up to 40 waves (between 1968 and 2018), combines seven countries, and includes around 2.7 million observations from almost 360 thousand respondents (Table 1). CPF version 1.0 covers the period until 2018. The oldest survey is PSID starting in 1968 and collecting 40 waves. The second oldest is SOPE which started in 1984 and so far, collected 35 waves. The youngest panel study in CPF is HILDA with 18 waves since 2001.

Table 1. Number of waves, observations and respondents

\begin{tabular}{llllllll}
\hline & & First & No of & \multicolumn{2}{c}{ Observations } & \multicolumn{2}{c}{ Unique respondents } \\
Country & Survey & wave & waves & $n$ & $\%$ & $n$ & n \\
\hline [1] Australia & HILDA & 2001 & 18 & 257,418 & 9.6 & 30,576 & 8.5 \\
[2] Korea & KLIPS & 1998 & 21 & 257,495 & 9.6 & 23,535 & 6.5 \\
[3] USA & PSID & 1968 & 40 & 457,638 & 17.0 & 42,219 & 11.7 \\
[4] Russia & RLMS & 1994 & 23 & 274,914 & 10.2 & 44,559 & 12.4 \\
[5] Switzerland & SHP & 1999 & 20 & 146,765 & 5.4 & 21,900 & 6.1 \\
[6] Germany & SOEP & 1984 & 35 & 675,693 & 25.1 & 94,525 & 26.3 \\
[7] UK & BHPS/UKHLS* & 1991 & 26 & 626,787 & 23.2 & 102,605 & 28.5 \\
\hline Total & & & & $2,696,710$ & 100 & 359,919 & 100 \\
\hline
\end{tabular}

* BHPS: 1991-2008, 18 waves, UKHLS: from 2009, 8 waves 
An average respondent participated in 7.5 waves (between 6.2 in Russia and 10.9 in South Korea). As shown in Figure 2, out of all 359,919 respondents, 91,625 participated in a minimum of 10 waves and 28,209 in a minimum of 20 waves. Country-specific lines indicate the exact number of waves for which the dataset provides information on sample members. For example, there are almost 22,000 respondents in the UK who participated in only one wave and nearly 16,000 who participated in exactly nine waves. In Australia, $18 \%$ of the sample (ca. 5,500 respondents) participated in all 18 waves of HILDA.

Figure 2. Number of waves in which individuals participated: exact number by the survey (left axis) and minimum number for the total sample (right axis)

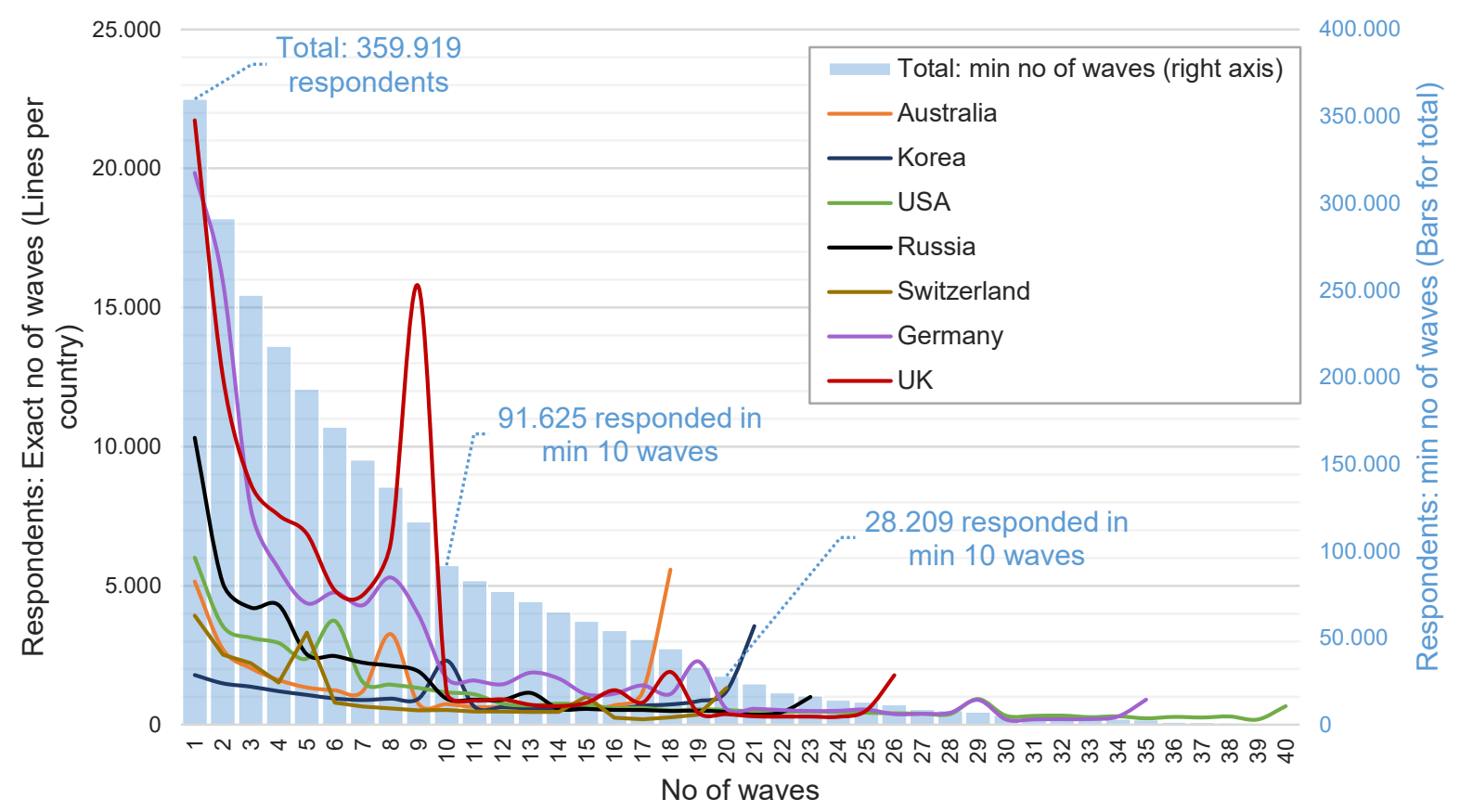

The oldest survey in CPF is PSID covering a period from 1968 and collecting 40 waves until now (Figure 3). The youngest panel study in CPF is HILDA with 18 waves since 2001. Since the wave of 2000, the number of participants in SOEP has grown significantly. CPF includes four countries since 1994, five countries since 1999, and all seven countries since 2001. A particularly large increase observed for the UK sample in 2009 is related to the transition from BHPS to UKHLS. For most of the surveys, data have been collected yearly (after 1997, PSID has switched to 2-year intervals in data collection). 
Figure 3. Timeline of the data and number of observations by wave

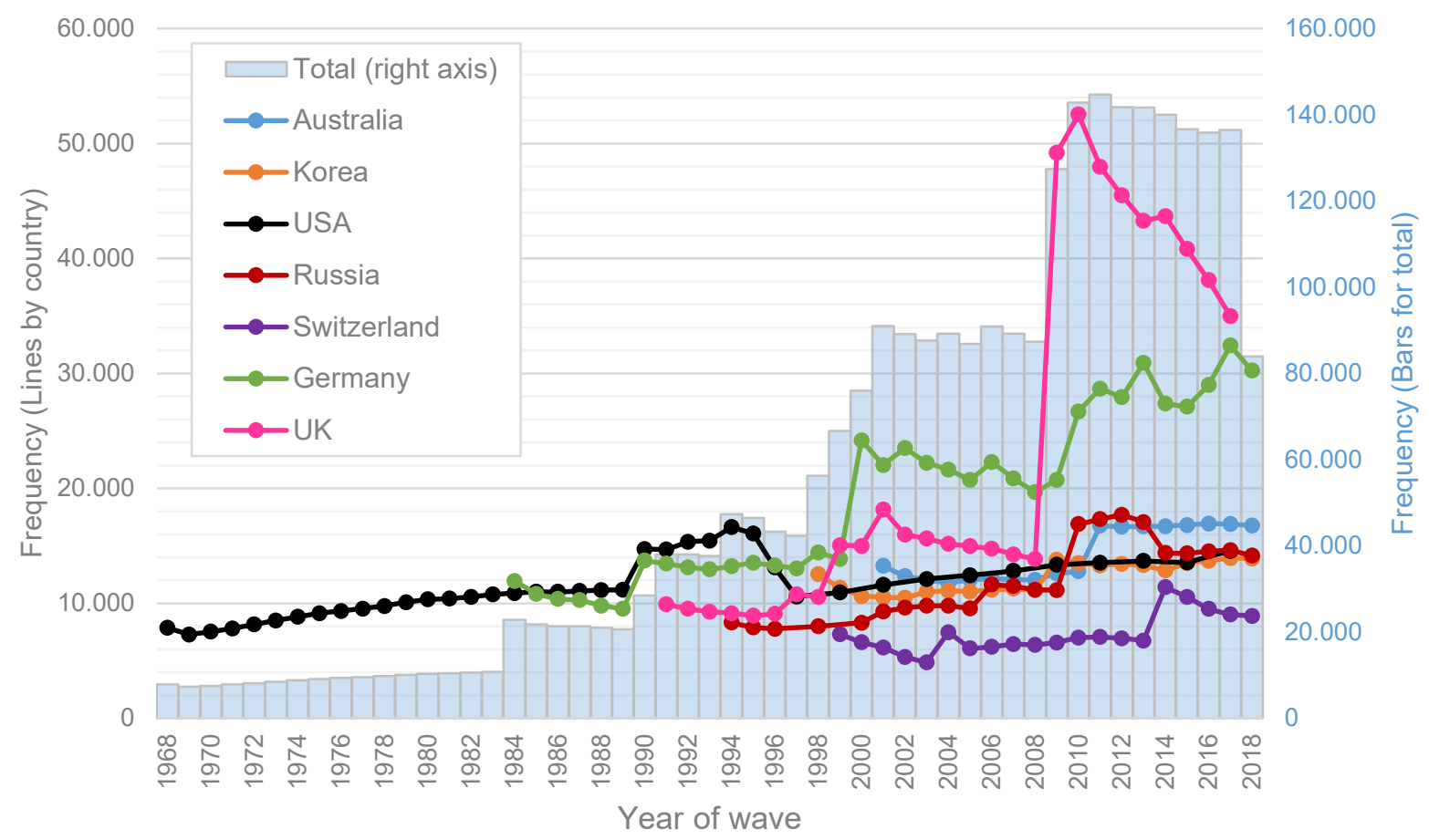

\section{Variables}

The goal of CPF is to harmonise variables across surveys. We based our approach on the CNEF but aimed at extending the range of variables included. For example, instead of a simple indicator for being employed or not employed, CPF provides a full range of labour market statuses, including being unemployed, retired, in education, or inactive. Instead of years of schooling, CPF focuses on education level according to the ISCED classification, a measure that has been designed for cross-national comparison. We provide more detailed information on marital status. CPF provides a set of additional variables, such as training participation, satisfaction with different domains, social origin, labour market experience, self-employment and entrepreneurship, work-education skill fit, and perception of job security. An overview of all variables is presented in Table 2.

For harmonisation, we explored the items available in the source data for their comparative potential. Some questions had a very similar form across all surveys (e.g., self-rated health), but many differed in the wording or number of answer categories. In the latter case, we assessed the comparative value and compared distributions of responses. It is important to keep in mind that descriptive statistics of 
harmonised variables may differ across countries if the original variables had different numbers of answering categories in different countries (Revilla, Saris, \& Krosnick, 2014). Similarly, differences in the wording of questions may produce (probably small) differences in the frequency distributions. Correlations with other variables are not necessarily affected by such differences (Kaminska \& Lynn, 2017; Slomczynski \& Tomescu-Dubrow, 2019; Wolf, Joye, Smith, \& Fu, 2017). We advise users to read the Codebook closely to be aware of such differences.

Full harmonisation was not always possible so that some variables are available for a subset of countries. Many of the CPF variables are composed of multiple source variables. For example, retirement is based on information about working status, self-reported retirement status, receiving retirement pension, and age. In many cases, the CPF's code includes data cleaning, such as updating contradictory entries with the most reliable information, filling missing values based on information from other waves or other variables (e.g., for education, age, year of birth, marital status). Users can modify existing or add further variables from the source data by developing the open CPF code (the procedure is described below in Workflow $D$ ). Detailed information on all variables is provided in the CPF Codebook (www.cpfdata.com).

Table 2. Variables available in the CPF version 1.0

\begin{tabular}{|c|c|c|}
\hline $\begin{array}{l}\text { Group of } \\
\text { variables }\end{array}$ & Description & Main variables \\
\hline Technical & $\begin{array}{l}\text { Respondent identifiers, information about wave and interview and } \\
\text { other technical information }\end{array}$ & $\begin{array}{l}\text { - } \text { - Pountry } \\
\text { - Personal and household identification numbers } \\
\text { - Wave's number and year } \\
\text { - Interview status } \\
\text { - Year and month of interview } \\
\text { - Sample identifiers }\end{array}$ \\
\hline Demographic & Basic demographic characteristics. & $\begin{array}{l}\text { - Gender } \\
\text { - Age } \\
\text { - Year of birth }\end{array}$ \\
\hline Education & $\begin{array}{l}\text { Education level is harmonised using the ISCED classification in four } \\
\text { different versions with three, four, and five levels. For example, } \\
\text { three levels are: [0-2] Low, [3-4] Medium, [5-8] High. Variables also } \\
\text { include years of education, participation in training, self-assessment } \\
\text { of qualifications. }\end{array}$ & $\begin{array}{l}\text { - Education: } 3 / 4 / 5 \text { levels } \\
\text { - Participation in training in the past } 12 \text { months } \\
\text { - Work-education skill fit } \\
\text { - Qualifications for job }\end{array}$ \\
\hline $\begin{array}{l}\text { Marital and } \\
\text { relationship } \\
\text { status }\end{array}$ & $\begin{array}{l}\text { CPF distinguishes between formal marital status and partnership } \\
\text { living-status, which also accounts for living with the partner. } \\
\text { Additionally, it includes less precise primary partnership status } \\
\text { equivalent to the one used in CNEF. Also, it provides indicators for } \\
\text { specific statuses (e.g. divorced) and being never married. }\end{array}$ & $\begin{array}{l}\text { - Formal marital status } \\
\text { - Partnership living-status } \\
\text { - Primary partnership status } \\
\text { - Living with the partner } \\
\text { - Never married } \\
\text { - Widowed } \\
\text { - Divorced } \\
\text { - Separated }\end{array}$ \\
\hline $\begin{array}{l}\text { Number of } \\
\text { children and } \\
\text { household } \\
\text { members }\end{array}$ & $\begin{array}{l}\text { There are several children-related variables to account for } \\
\text { differences in questionnaires in: } \\
\text { - } \text { the definition of children, e.g. own-born, adopted, of other family } \\
\text { members, any children }\end{array}$ & $\begin{array}{l}\text { - Number of children in household (aged 0-15, 0- } \\
\text { 17) } \\
\text { - Number of children ever had } \\
\text { - Has own children (yes/no) } \\
\text { - Number of people in household }\end{array}$ \\
\hline
\end{tabular}




\begin{tabular}{|c|c|c|}
\hline $\begin{array}{l}\text { Group of } \\
\text { variables }\end{array}$ & Description & Main variables \\
\hline & $\begin{array}{l}\text { - the situation of children, e.g., living currently in the household, } \\
\text { living elsewhere, children ever had } \\
\text { - } \text { age of children, e.g., any age, below 18, and below } 15 \text { years old }\end{array}$ & \\
\hline \multirow{8}{*}{$\begin{array}{l}\text { Labour } \\
\text { market } \\
\text { situation and } \\
\text { employment }\end{array}$} & $\begin{array}{l}\text { An important goal of the CPF is to provide a comprehensive view of } \\
\text { individuals' labour market situation. These include the following } \\
\text { areas: }\end{array}$ & \\
\hline & $\begin{array}{l}\text { Labour market situation: employed, unemployed, retired or } \\
\text { disabled, in education, not active, employed but on leave. CPF also } \\
\text { identifies maternity leave. }\end{array}$ & $\begin{array}{l}\text { - Labour market situation (5/6 categories) } \\
\text { - } \quad \text { Currently working (self-reported) } \\
\text { - } \text { Working in the previous year (based on reported } \\
\text { working hours) } \\
\text { - } \quad \text { Being on maternity leave } \\
\text { - } \quad \text { Never worked }\end{array}$ \\
\hline & $\begin{array}{l}\text { Level of employment: full- or part-time, number of working hours } \\
\text { (several versions, including actual and contracted hours) }\end{array}$ & $\begin{array}{l}\text { - Full- or part-time work (based on working hour / } \\
\text { self-reported) } \\
\text { - Number of working hours (per year, month, } \\
\text { week, day) } \\
\text { - Work hours per week: contracted }\end{array}$ \\
\hline & $\begin{array}{l}\text { Occupation - classified according to the International Standard } \\
\text { Classification of Occupations (ISCO). KLIPS and PSID use different } \\
\text { classifications than ISCO. In these cases, crosswalk algorithms were } \\
\text { developed. ISCO level } 1 \text { and } 2 \text { are harmonised for all countries, but } \\
\text { if available, CPF provides a more detailed classification in versions } \\
\text { ISCO-88 or ISCO-08 at 3- or 4-digit levels. }\end{array}$ & $\begin{array}{l}\text { - Occupation: ISCO level 1: } 1 \text { digit, } 10 \text { categories } \\
\text { - Occupation: ISCO level 2: } 2 \text { digits, } 50+\text { categories } \\
\text { - Additionally, ISCO-08/ ISCO-88 with } 3 \text { or } 4 \text { digits } \\
\text { - Supervisory position }\end{array}$ \\
\hline & Characteristics of the employee's organisation. & $\begin{array}{l}\text { - Industry: } 3 \text { major, } 10 \text { sub-major and } 17 \text { minor } \\
\text { groups } \\
\text { - } \text { Sector (public) } \\
\text { - }\end{array}$ \\
\hline & $\begin{array}{l}\text { More precise and specific identification of actively unemployed, } \\
\text { self-employed, entrepreneurs (with employees), and retirees. These } \\
\text { indicators are built on information from several variables. For } \\
\text { example, individuals are classified as retired when they are not } \\
\text { working and meet any of the following criteria: } \\
\text { - Self-categorisation as retired \& age 50+ } \\
\text { - Receives old-age pension \& age 50+ } \\
\text { - Age 65+ }\end{array}$ & $\begin{array}{l}\text { - Unemployed: actively looking for work } \\
\text { - Self-employed } \\
\text { - } \text { Entrepreneur (including or not including farmers) } \\
\text { - } \text { Retired fully } \\
\text { - }\end{array}$ \\
\hline & Labour market experience measured as years of employment/work & $\begin{array}{l}\text { - Total Labour market experience (total/ full time } \\
\text { / part time) } \\
\text { - Tenure with current employer }\end{array}$ \\
\hline & $\begin{array}{l}\text { Perception of job security - Whether the respondent is worried } \\
\text { about job security (in two versions) }\end{array}$ & $\begin{array}{l}\text { - Secure /Insecure } \\
\text { - Secure /Insecure / Hard to say }\end{array}$ \\
\hline Incomes & $\begin{array}{l}\text { Incomes of individuals and households. Depending on the original } \\
\text { data, information on individual income is included in several } \\
\text { variables based on: } \\
\text { - source of income (total income from jobs and benefits, from all } \\
\text { jobs, from the main job) } \\
\text { - type of income (gross, net) } \\
\text { - reference period for income (year, month, per hour) } \\
\text { This approach results in multiple variables but provides clear } \\
\text { definitions. For analytical purposes, users can combine particular } \\
\text { variables using the nominal values or relative values (e.g., } \\
\text { percentiles). CPF provides values as they are included in the source } \\
\text { data, without any additional cleaning, imputation, conversion or } \\
\text { inflation-adjustments. Values are in local currency. } \\
\text { Depending on the type of monthly household income in the original } \\
\text { data, information is provided in two versions: before taxes and } \\
\text { deduction (gross, pre), after taxes and transfers (net, post). Some } \\
\text { datasets provide a negative household income indicating a loss or } \\
\text { debit (e.g. PSID since 1994). Values are in local currencies. }\end{array}$ & 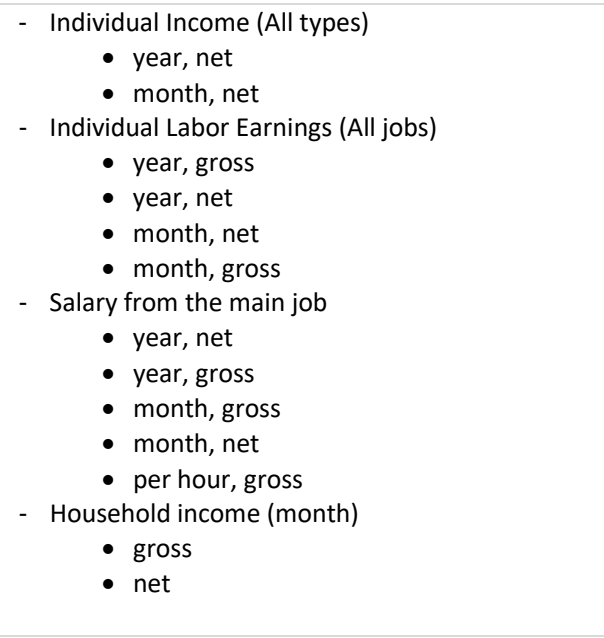 \\
\hline $\begin{array}{l}\text { Health and } \\
\text { wellbeing }\end{array}$ & $\begin{array}{l}\text { Self-rated health status is based on the standard 5-point scale. } \\
\text { There are three versions of disability-related questions. }\end{array}$ & $\begin{array}{l}\text { - Self-rated health } \\
\text { - Receiving disability pension }\end{array}$ \\
\hline
\end{tabular}




\begin{tabular}{|c|c|c|}
\hline Group of & Description & Main variables \\
\hline & $\begin{array}{l}\text { Variable for chronic diseases is in a working version: it is not fully } \\
\text { harmonised and should be modified by the users according to } \\
\text { specific conceptual framework (e.g. defining chronic conditions). } \\
\text { CPF provides several dimensions of subjective wellbeing, which can } \\
\text { be harmonised for at least several countries. We include two versions } \\
\text { of each variable due to differences in original answer scales: with a } \\
5 \text {-point scale ( } 1-5 \text { range) and 11-point ( } 0 \text {-10 range). If required, the } \\
\text { original values were rescaled. }\end{array}$ & $\begin{array}{l}\text { - Disability: any type (physical, mental or nervous } \\
\text { condition) } \\
\text { - Disability: min. category } 2 \text { or }>30 \% \\
\text { - Chronic diseases (yes / no) } \\
\text { - Satisfaction with } \\
\text { - Life } \\
\text { - Work } \\
\text { - Financial situation of household } \\
\text { - Individual income } \\
\text { - Family } \\
\text { - Health }\end{array}$ \\
\hline $\begin{array}{l}\text { Parental } \\
\text { background }\end{array}$ & $\begin{array}{l}\text { Parents' education level is coded in 3- and 4-categorical variables } \\
\text { similarly to respondent's education level. }\end{array}$ & - Mother's / Father's education: 3 /4 levels \\
\hline $\begin{array}{l}\text { Socio- } \\
\text { economic } \\
\text { position }\end{array}$ & $\begin{array}{l}\text { Socio-economic position scales are based on respondents' work } \\
\text { status and occupation's ISCO code. }\end{array}$ & $\begin{array}{l}\text { - International Socio-Economic Index of } \\
\text { occupational status (ISEI) } \\
\text { - Treiman's international prestige scale (SIOPS) } \\
\text { - } \text { German Magnitude Prestige Scale (MPS) }\end{array}$ \\
\hline
\end{tabular}

\section{Samples}

In the default settings, CPF includes observations from individuals aged 18 and older and meet the following criteria:

1. Interview status:

a. South Korea, Russia, Switzerland, the UK: keep all observations (including proxy responses)

b. Australia, Germany: keep direct respondents only

c. The US: only reference persons (heads) and partners (spouses) (see details on PSID for explanation)

1. Age: 18 and older

2. Delete observations with missing values for gender and age (a minor correction)

Users can easily modify these selection criteria (see: Workflow D - Adjustments to sampling criteria). 


\section{How to work with the CPF syntax}

The CPF provides the syntax (programming code in Stata do-file format), the Manual explains how to work with the syntax, and the Codebook describes all variables. The code allows combining the separate raw survey data into a single harmonised data file. A step-by-step guideline of how to work with the CPF is presented in Figure 4. Users must first apply for access to each of the original datasets (see: Obtaining the original data). When access is granted, the first syntax can be run to set up a folder structure where original survey files can be extracted. Then, users can easily follow the instructions to build the comparative file in the default way or modify the procedures according to their needs. In the latter case, the hierarchical design of the code allows locating all the steps in the algorithms easily. Country-specific syntaxes are commented and organised in a similar way to facilitate the work.

Figure 4. A step-by-step guide through using the CPF code

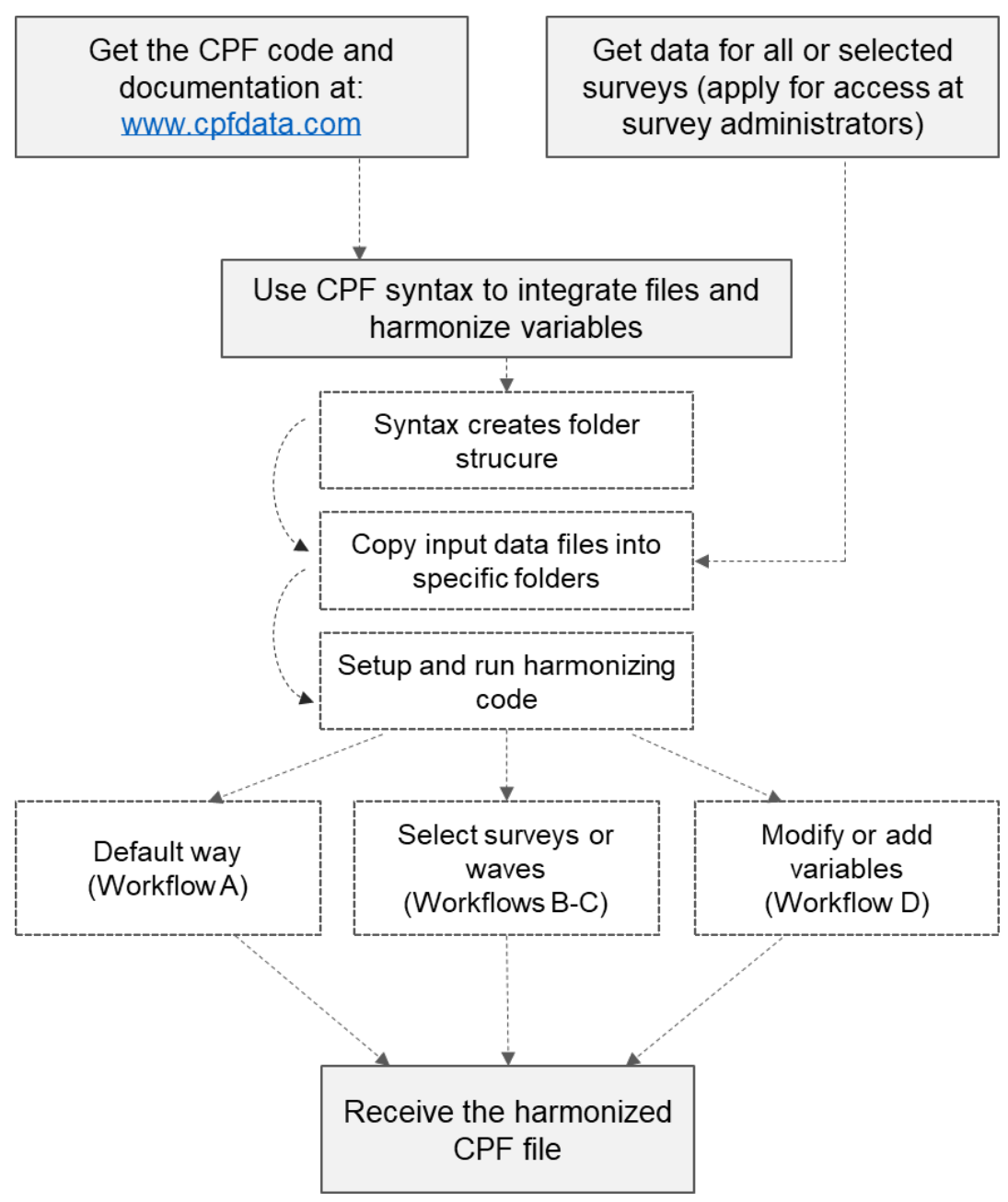


There are four general ways of working with the CPF syntaxes (workflows). Workflow $A$ describes the basic approach which constructs the data without any modifications. Workflows $B, C$ and $D$ refer to different modifications of the existing syntaxes, with Workflow $D$ being the most flexible and advanced. All approaches are described in the following paragraphs. More details are in the syntax's comments which additionally include references to the workflows $A-D$ to highlight places which might require adjustments.

\section{Basic workflow A: Three steps to get the CPF data}

The basic way of working with the CPF syntax leads from the raw data to a CPF harmonised dataset without any modifications (such as modifying variables, adding new variables, adding new waves, or selecting countries - for these see the next part). The approach requires only to use two higher-level syntaxes ( 1 and 2 ). Workflow A consists of three basic steps, as presented in Figure 5 :

Figure 5. The basic way of working with the CPF syntax (workflow A)

\section{Workflow A}

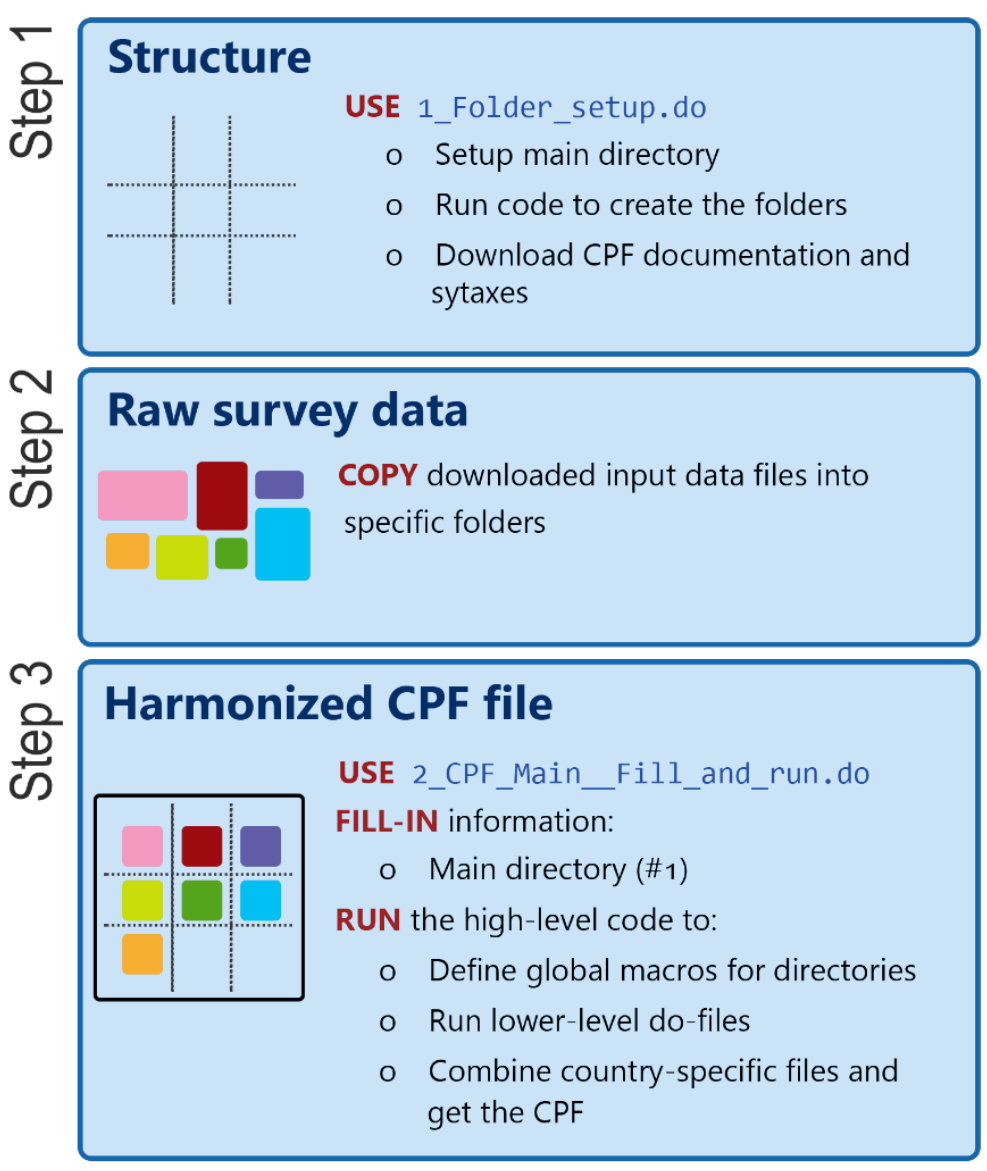


Users first have to fill in the necessary information, such as the directory in the first syntax (1_Folder_setup.do) and run it to create an appropriate folder structure (see the part on Folder Structure). Then, they can place the downloaded data in specific folders of the 02_Country_Data_Origin main folder. There is a separate subfolder for each survey (e.g. 01_HILDA) with a subfolder Data, where the files should be copied, e.g. 02_Country_Data_Origin\01_HILDA\Data (see details in Obtaining original data). The next step uses the second syntax (2_CPF_Main__Fill_and_run.do)

The third step uses syntax 2_CPF_Main__Fill_and_run.do to call all lower-level syntaxes (_10,_11,_12, and_13). Users only have to fill the address of the main directory in \#1. (Also check the information on the number of waves in \#3 and file names in \#4 - see Workflow C). With these information, the code in parts \#5-\#7 can be simply run to activate lower-level syntaxes $\left(\_10, \ldots 11, \ldots 12\right.$, and $\left.\_13\right)$. Within this structure, syntax_11 calls all country-specific syntaxes (multiple do-files numbered_01,_02,_03). Note that operations - especially in \#6 - are complex and running the code can easily take an hour or two on an average computer. More details are in the syntax's comments. For any modifications or problems, refer to workflows B, C or D. 


\section{Advanced workflows B, C and D: Modifying and adding data}

The other workflows can be used if users wish to modify or add data (Figure 6).

Figure 6. Advanced ways of working with the CPF syntax (workflows $B, C$ and $D$ )

\section{Selecting countries}

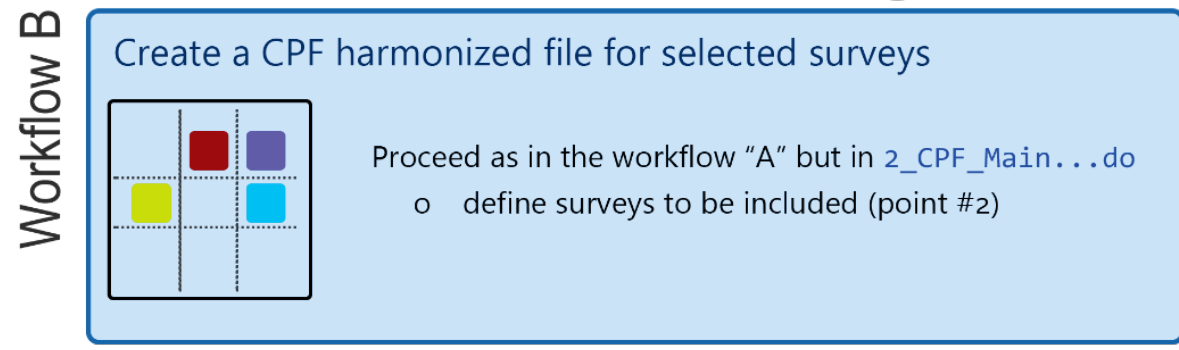

Adding new waves

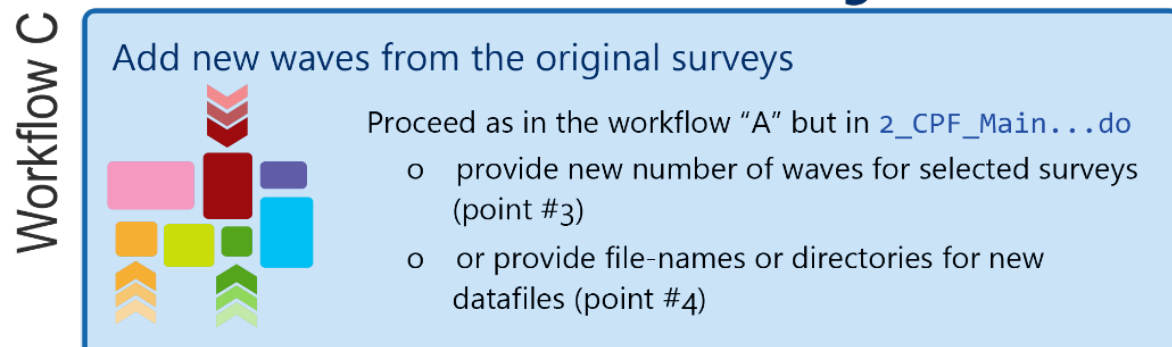

\section{Modifying or adding variables}

Modify CPF variables or add new ones from the original
survey data

\section{Workflow B}

Workflow $B$ allows selecting surveys to be included in the harmonised CPF dataset by changing the list of surveys in syntax 2 . This option can be useful for users who do not have access to all surveys or have no need to harmonise all of them. The only difference in the procedure compared to Workflow $A$, is to define surveys to be included in 2_CPF_Main_Fill_and_run.do (point \#2). For example, to keep all surveys, simply leave all their names in the global macro (use lowercase): 


$$
\text { global surveys "hilda klips psid rlms shp soep ukhls" }
$$

To select only PSID, RLMS and UKHLS, keep only respective names in the code:

$$
\text { global surveys "psid rlms ukhls" }
$$

The rest of the procedure is limited to the default running of the entire code in syntax 2.

\section{Workflow C}

Workflow $C$ serves to add new waves when they become available for the surveys. The CPF code will be regularly adjusted to incorporate new waves, however, some users might want to modify the syntaxes on their own. In most of cases, the procedure should be easy and limited to filling-in information in 2_CPF_Main_Fill_and_run.do on the number of waves in \#3 (for HILDA, KLIPS, SHP, SOEP and UKHLS) and file names in \#4 (for RLMS, UKHLS and PSID).

The new number of waves for selected surveys should be filled in in point \#3, e.g.:

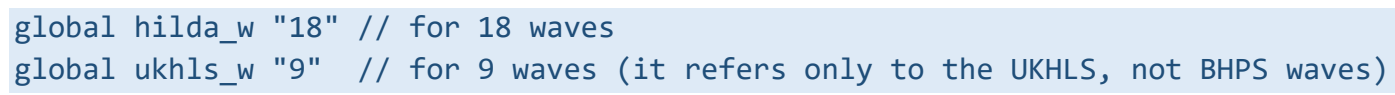

This approach does not apply to RLMS and PSID, for which the procedure is different. Data for RLSM is downloaded as a multi-wave dataset, so updating it with new waves only requires only to update the filename (point \#4), e.g.:

$$
\begin{aligned}
& \text { global rlms_dataIND "USER_RLMS-HSE_IND_1994_2018_v2_eng_STATA.dta" } \\
& \text { global rlms_dataHH "USER_RLMS-HSE_HH_1994_2018_eng.dta" }
\end{aligned}
$$

For PSID, the adding new waves in more complex and must be done manually for each variable (see: Survey-specific details on PSID). The latest name of the individual dataset has to be added in:

$$
\text { global psid_ind_er "\$\{psid_in\}\pack \IND2017ER.txt", clear }
$$

Additionally, new waves of UKHLS may require to update a directory for the data files (point \#4), e.g.:

$$
\text { global ukhls_data "UKDA-6614-stata\stata\stata11_se" }
$$

Note that releases of the new waves can also bring changes to the original data structure which do not fit the current CPF algorithms, such as changes in names of variables, files or directories. In such cases, additional adjustments have to be made in higher-level syntax 2 and/or lower-level syntaxes_ 01 (see Workflow D). For PSID, adding new waves is more complicated because the names of variables in new waves change and must be updated in the code manually (see: Survey-specific details on PSID). 


\section{Workflow D}

Workflow D refers to all other modification of the existing structure of the CPF data. Users can modify variables, add new ones, or modify the criteria for sample selection. Any adjustments of this type must be made in the lower-level syntaxes, separately and consistently for all surveys and for the master-syntaxes. Depending on the character of modifications, the procedure can be easy or complicated.

\section{Adjustments to variables}

1. When adding or modifying variables, users should:

- Carefully explore questionnaires, codebooks and data

- Assess the consistency of original variables across waves

- Assess the consistency of new variables between countries

- Perform check-up of the new variables within a country (logical rules, distributions, crosstabulations)

2. Adjustments to variables must be first introduced in the survey-specific syntaxes 01 and 02 stored in the survey-folders (e.g. 11_CPF_in_syntax\01_HILDA). Note, that for some surveys there are multiple syntaxes at levels 01 and 02 . The main steps include:

- New variables can be added to the main CPF dataset using do-files 01 . The procedure depends on the structure of the original data. For most of the surveys (HILDA, KLIPS, RLMS, UKHLS), all original variables are already available in the $\mathbf{x x}_{\mathbf{0}} \mathbf{0 1} \mathbf{1} \mathbf{d t a}$ file created with the 01 syntaxes (note that code for UKHLS drops some variables at the end). SOEP and SHP require to add variables from multiple source datafiles using 01 code. The procedure is more complex for PSID, where a whole set of variable names has to be added (so-called item-blocks) using 01_3. More details can be found in survey-descriptions and instruction in the do-files.

- Modifications of the new or existing variables (such as recoding, combining multiple variables, renaming etc.) can be done in do-files 02 . This is a place to harmonise the variables across surveys.

- Always include new or modified variable names in the keep commands at the end of the file.

- Syntaxes 03 do not have to be adjusted in case of variable-level modification.

3. Further on, users have to adjust the master (between-surveys) syntaxes _ 12 - _ 13 stored in the 11_CPF_in_syntax \00_master folder as follows: 
- New or modified variables must be added to the keep code after appending data in _12.

- Then, appropriate labels must be included in _13.

\section{Adjustments to sampling criteria}

Adjustments to the sampling criteria can be done in syntaxes 03 separately for each survey. They should not require additional modifications in other syntaxes.

\section{Computer requirements}

The CPF code is available in Stata, and it has been prepared in Stata 16. Running the entire code can easily take an hour or two on an average computer. Faster processor and more working memory will speed up the process. It is recommended to have at least $80 \mathrm{~GB}$ storage hard drive space if all countries are included (the original data files require minimum $50 \mathrm{~GB}$ and the CPF working and output files need additional 25 GB). 


\section{CPF syntax: design, details and advanced options}

\section{Folder structure}

In order to run the CPF code, users must first create a folder structure as presented in Figure $\mathrm{X}$. It is done automatically by running 1_Folder_setup.do:

1. First, insert the directory to your CPF folder in \#1 ("Your local directory"), e.g.:

global your_dir " D:\CPF" // <--insert your directory

2. Running the rest of the code (\#2-\#3) will create appropriate folders.

3. Then you can copy the original input datafiles to specific folders

Figure 7. Structure of the folders required for the CPF algorithms

\begin{tabular}{|c|}
\hline $\begin{array}{r}\text { Your main dire } \\
\text { (e.g. "D: }\end{array}$ \\
\hline 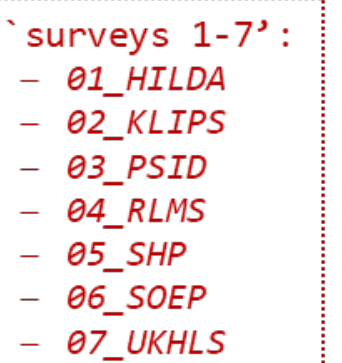 \\
\hline
\end{tabular}
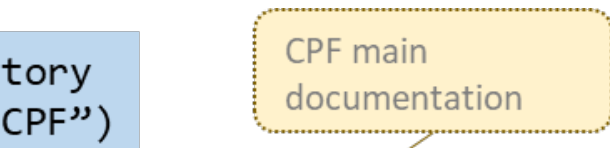

01_CPF_docs

Original input data downloaded by the user

\section{2_Country_Data_Org}

11_CPF_in_syntax

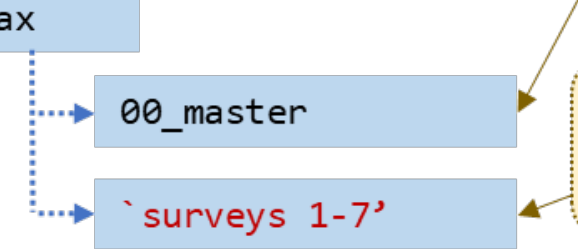

12_CPF_out_data 'surveys $1-7^{\prime} \backslash$ data
Single survey output CPF data
Main (higher-

level) syntaxes to be run by the user

Survey-specific (lower-level) syntaxes

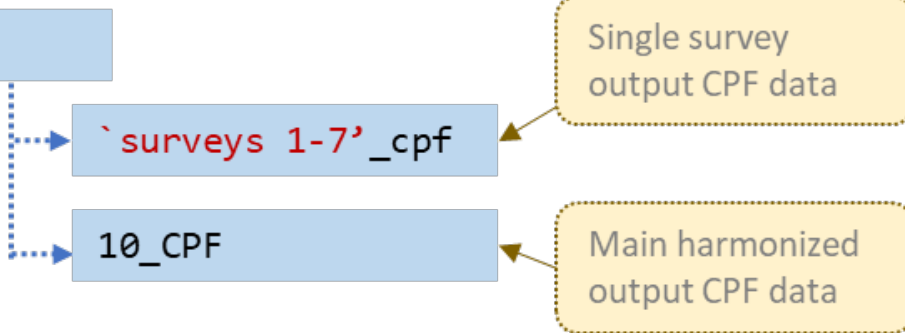




\section{Syntax: higher and lower-level code}

CPF syntaxes (codes) are designed at two levels: higher and lower (Figure 8). Two higher-level syntaxes are: 1_Folder_setup.do to set up the directory and folder structure, and 2_CPF_Main_Fill_and_run.do to harmonise the dataset. These are short meta-code and do not refer directly to variables or data files. Instead, they work as an interface and allow to fill in the necessary information (e.g. file directory) and setup options for harmonisation (e.g. which surveys to include). Higher-level syntaxes call all the required code of a more complex structure of lower-level syntaxes.

For each survey, there are separate lower-level syntaxes, and the algorithms are designed differently. However, they all lead through the same three steps: the first constructs initial separate country data in a long format by merging original files, the second harmonises variables within countries according to the common template, and the third selects comparative samples. The process results in separate datasets with the same data structure for each country. Then, all country files can be combined into the single CPF harmonised dataset using a higher-level syntax.

Users can easily follow the instructions to build the comparative file in the default way (Workflow A) or modify the procedures according to their needs. In the latter case, the hierarchical design of the code allows locating all the steps in the algorithms quickly. Country-specific syntaxes are commented and organised in a similar way to facilitate the work. Many users can be interested in syntaxes_01 which contain code that integrates all raw files into single and ready for analysis (yet un-harmonised) country data sets. 
Figure 8. Structure of the higher and lower level syntaxes

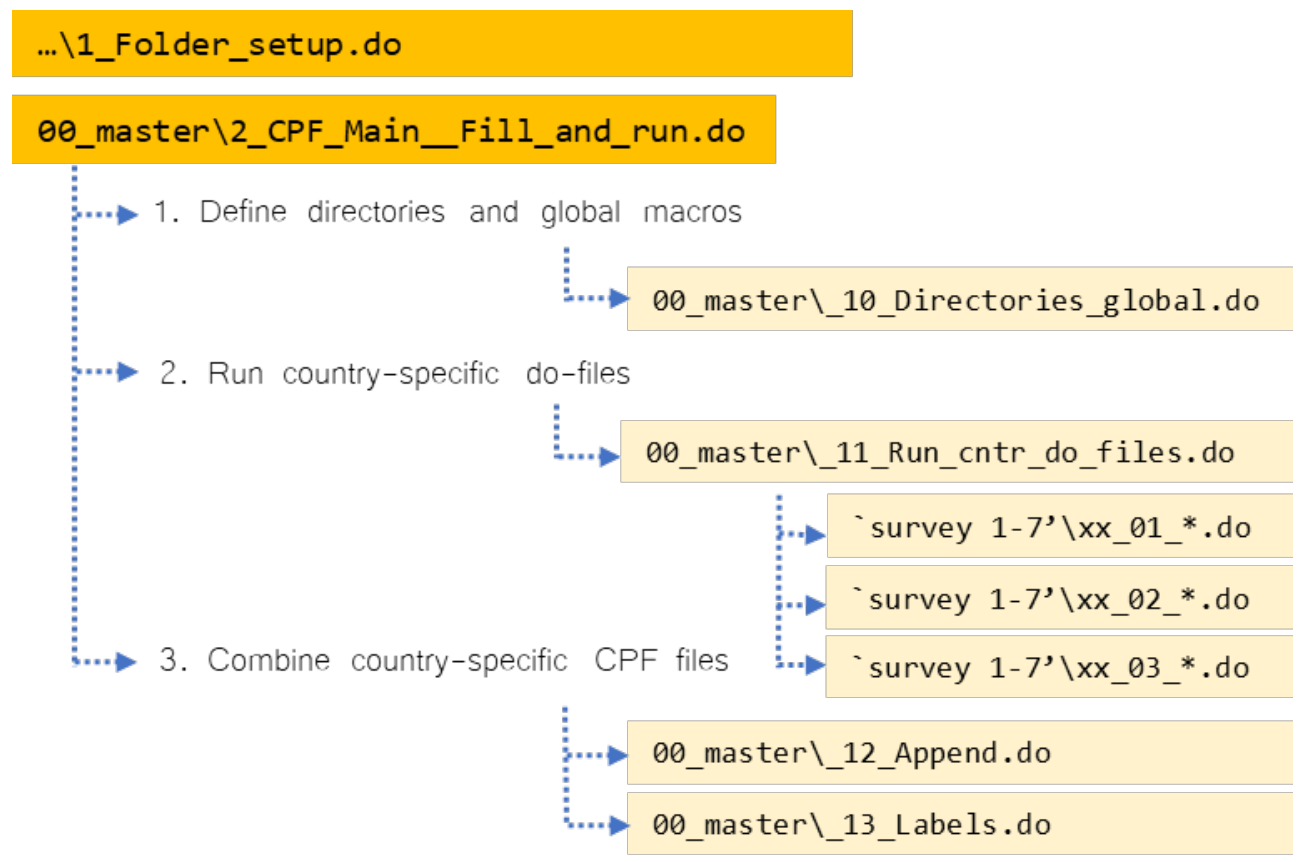

Higher-level sytax To be run by the user
Lower-level sytax $\quad$ Modify only if necessary

\section{Design of the lower-level code}

Harmonisation of the data is done in four steps using a lower-level syntaxes specific for each survey (stored in 11_CPF_in_syntax\`survey’ ). The first step is to construct the base separate-country data in a long format, the second - to harmonise variables within a country-files, the third - to select the sample, and the fourth - to combine all country files into a single CPF harmonised dataset. All of these steps can be run from the higher-level syntax 2_CPF_Main.... do.

Step 1. Preparation of the long format base-file for each country

- Input: original surveys' datafiles (stored in 02_Country_Data_Origin\`survey’\Data)

- Syntaxes: 11_CPF_in_syntax\'survey’ \xx_01_*.do

- Result: data file(s) in a long format: 12_CPF_out_data\`survey’_cpf $\backslash \mathbf{x x \_ 0 1 \_ * . d t a}$ 
First, for each country, we must construct the base-file in a long format, which contains all (or selected) source variables, as provided by the data supplier. A long-format of panel data means that the repeated observations are clustered by individuals so that each row of data refers to respondent's information from a specific wave (contrary to wide data, where wave-specific information is provided in separate variables, e.g. health_wave1, health_wave2).

The procedure is different for each country, and its complexity depends on the data structure. Most of the datasets require to combine (append and merge) separate files for specific waves and/or types of surveys (e.g. individual, household or topic-specific questionnaires). Codes for this stage often include a group renaming of variables to a format which is required in a long-format file (e.g. removing wavereference in variable names). For the PSID, the procedure is much more complicated, since it needs first to retrieve and combine sets of variables which refer to the same question or concept. The RLMS, on the other hand, is already provided in a long format for specific types of questionnaires. For some countries, a pre-selection of variables and initial cleaning is done at this stage. In addition to the raw data files, in some cases, CPF also uses selected CNEF variables (separate CNEF data files are provided for HILDA, SHP and SOEP).

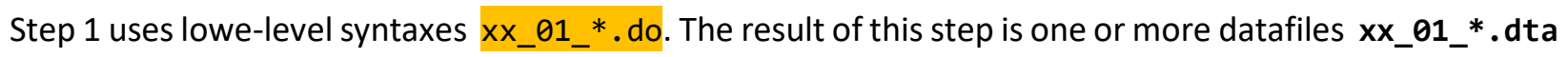
with a large number of non-harmonised variables in a long data format.

Step 2. Harmonisation of variables within a country

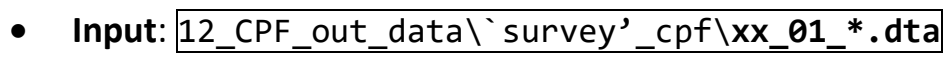

- Syntaxes: 11_CPF_in_syntax\'survey’ $\backslash x x \_02 \_*$.do

- Result: a single data file for each country with a harmonized variable structure 12_CPF_out_data\`survey’_cPf $\left.\backslash \mathbf{x x} \_02 \_C P F . d t a\right)$

In the second step, we use variables from the $\mathbf{x x \_ 0 1 \_ *}$.dta base-file(s) to construct new harmonized variables. The harmonised variables are the same for all countries in terms of names, format and response categories. However, some of them are available only for selected surveys.

The harmonisation process involves:

- Recoding and combining original variables into new variables

- When necessary, creating additional versions of variables (not fully harmonised) 
- Selecting additional variables to keep (e.g. weights, sample characteristics, other countryspecific variables)

- Basic data cleaning (which is not a full preparation for analysis)

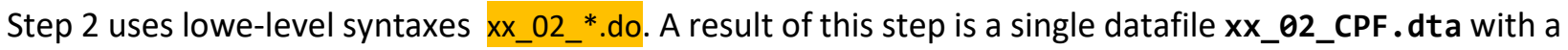
set of harmonised variables in a long data format.

Step 3. Sample selection

- Input: 12_CPF_out_data\`survey’_cpf $\backslash \mathbf{x x}$ _02_CPF.dta

- Syntaxes: 11_CPF_in_syntax\`survey’\xx_03_Sample_selection.do

- Result: a single data file for each country with a harmonized variable structure (12_CPF_out_data\`survey’_cPf $\backslash \mathbf{x x}$ _03_CPF.dta)

During the third step, we select the final sample to be included in the main CPF dataset. The selection is based on the interview status (keeping different types of interviewed respondents or proxy-interviews), age criteria (age 18+) and missing values (keeping individuals with information on age and gender). For some surveys, e.g. PSID or SOEP, selection of the sample is not straightforward, and users might want to adjust the criteria based on their research needs. Step 2 uses lower-level syntaxes xx_03_ Sample_selection.do. A result of this step is a single datafile $\mathbf{x x \_ 0 3 \_ C P F . d t a ~ w i t h ~ h a r m o n i s e d ~ s a m p l e ~}$ criteria.

Step 4. Combining country data into a one harmonised CPF dataset

- Input: harmonized separate survey datafiles 12_CPF_out_data\`survey’_cPf $\backslash \mathbf{x x} \_03 \_C P F . d t a$

- Syntaxes: 11_CPF_in_syntax\00_master\_12_Append.do and _13_Labels.do

- Result: a single CPF data file for all countries (12_CPF_out_data\10_CPF\CPFvX.X.dta)

Finally, all separate country-files with a harmonised structure of the data are merged into a single harmonised CPF dataset. It is done by running_12 syntax. Additionally, labels for variables and categories are added in syntax_13. The result is the final CPF dataset, e.g. CPFv1.0.dta. 


\section{Obtaining the original data}

Users must first apply for access to each of the original datasets independently at national administrator institutions. Access is free of charge, but in most cases, users must describe their research goals and sign a contract. When access is granted, data can be extracted to specific CPF subfolders in the 02_Cntry_Data_Orgin\`survey’ \Data folders, as explained below. With new waves, users have to modify global macros in \#3 of syntax 2 (see Workflow C), e.g.:

\section{global klips_w "21" // number of waves}

However, if the approach to naming variables, folders or datafiles in the original data changes in the future, additional adjustments have to be made in higher-level syntax 2 and/or lower-level syntaxes xx_01.

CPF version 1.0 was built on data versions released in 2020, i.e. HILDA ver. 180, KLIPS ver. 21, PSID ver. 2017, RLMS ver. 2018, SHP ver. 20, SOEP ver. 35, and UKHLS ver. 8. Backward compatibility with older releases may not be available for some variables or surveys due to changes in variables names and file structure (but the syntax can be modified). New waves will be continuously integrated into the CPF code; users can also do this independently (see Workflow C in Using the CPF syntax).

\section{1_HILDA - Australia}

Apply for the data via the National Centre for Longitudinal Data Dataverse (Australian Government Department of Social Services): https://dataverse.ada.edu.au/dataverse/ncld. Unpack downloaded files to subfolders for data types (as in the original compressed file), such as STATA 180c (1-Combined Data Files) and STATA 180c (2 - Other Data Files), e.g.:

$$
\begin{aligned}
& \text { 02_Cntry_Data_Orgin\01_HILDA\Data } \\
& \hookrightarrow \text { STATA 180c (1-Combined Data Files) } \\
& \hookrightarrow \text { Combined_r180c.dta } \\
& \hookrightarrow \text {... } \\
& \hookrightarrow \text { STATA 180c (2 - Other Data Files) } \\
& \hookrightarrow \text { Household_r180c.dta } \\
& \longrightarrow \ldots
\end{aligned}
$$


The number 180 in folders' names refers to the current version (number of waves) of HILDA which is filled in \#3 of syntax 2 as, e.g. 18 (see Workflow C):

$$
\text { global hilda_w "18" // version of HILDA, number of waves }
$$

The global is incorporated into the code of au_01_Prepare_data. do to refer to the appropriate directory.

\section{2_KLIPS - South Korea}

Data are available via the official website for registered users: www.kli.re.kr/klips eng. Unpack all downloaded files in a subfolder as in the original compressed file, such as Stata 1-21, e.g.:

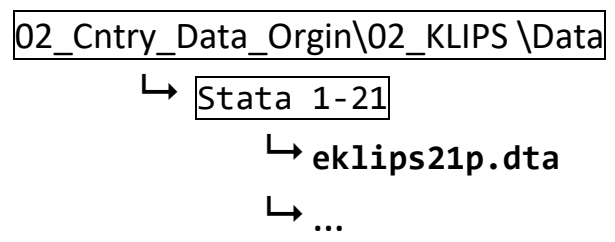

With new waves, users have to modify global macros in \#3 of syntax 2 (see Workflow C), e.g.:

$$
\text { global klips_w "21" // number of waves }
$$

03_PSID - US

The logic behind PSID differs from other datasets and is much more complex (see Survey-specific details for PSID). To organise the data, we use psidtools ado (Kohler, 2015$)^{6}$, which can be downloaded using:

ssc install psidtools

Data are available via the official website for registered users:

https://simba.isr.umich.edu/Zips/ZipMain.aspx:

1. Download all Family Files (one per wave, e.g. fam2017er.zip) and place them in into Family and Ind Files (zip). Do not unpack.

2. Download Cross-year Individual: 1968-XXXX zipped file and place it in Family and Ind Files (zip). Do not unpack.

3. Leave all files in the Family and Ind Files (zip) folder unpacked but additionally unpack the Cross-year Individual: 1968-XXXX zipped file (e.g. ind2017er.zip) to Data/Cross-year

\footnotetext{
${ }^{6}$ PSIDTOOLS is Stata' module to facilitate access to PSID, developed by Ulrich Kohler from the University of Potsdam. See: https://ideas.repec.org/c/boc/bocode/s457951.html.
} 
Individual 1968-XXXX/pack. It should contain a txt file with vales named, e.g. IND2017ER.txt (which you define in 2 as global psid_ind_er “\$\{psid_in\}\pack\IND2017ER.txt”).

CPF syntax manages further reorganisation of the files. E.g. after running the lower-level syntaxes 01 for PSID, the code will unpack and combine required files into PSIDtools_files folder, and syntax 03 will create a number of item-specific files in the temporary directories.

After downloading, the PSID data-folder should look as following:

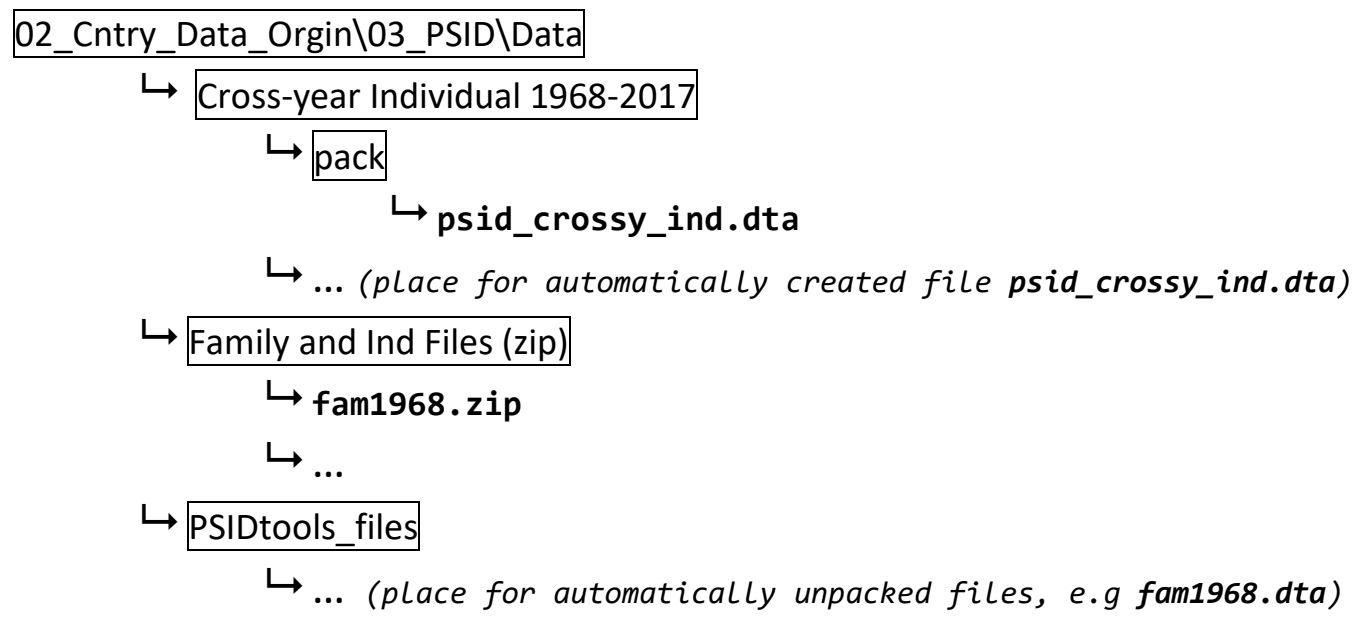

The data are available via the Higher School of Economics (HSE) without application: www.hse.ru/en/rlms. Additionally, the data may be downloaded at the Carolina Population Center (CPC) without application: www.cpc.unc.edu/projects/rlms-hse/data. There should be two multi-wave files in long-data formats: for the individuals and households. Unpack them into the main Data folder, e.g.:

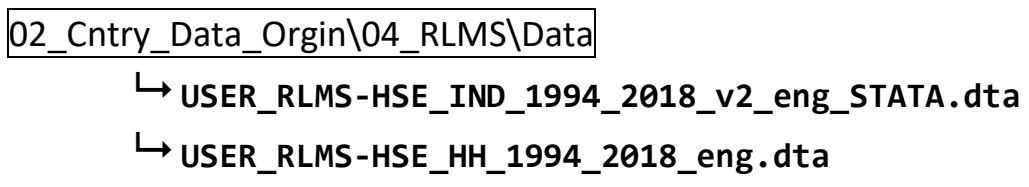

Names of the files can differ depending on the source (HSE or CPC). Both for the individual and household files, the names have to be properly included in syntax 2_CPF_Main_Fill_and_run.do in \#4, e.g.:

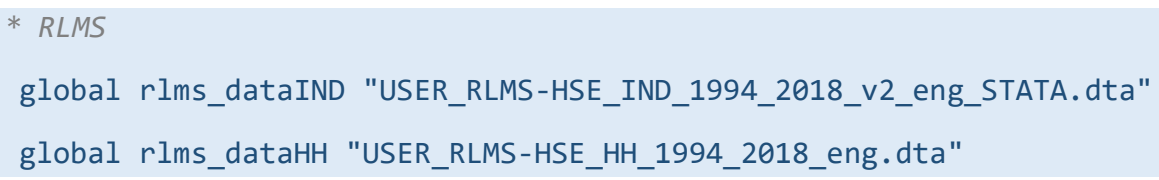




\section{5_SHP-Switzerland}

Data are available via FORSbase for registered users: https://forscenter.ch/projects/swiss-householdpanel/data. Unpack all folders from Data_STATA.zip into the main Data folder. It should then contain several folders with different types of datasets. The main source of the individual- and household-level data are files in SHP-Data-W1-W20-STATA folder (e.g. shp99_P_user.dta). Additionally, CPF refers to other folders, including SHP-Data-CNEF-STATA and SHP-Data-WA-STATA. After unpacking, the structure should look as follows:

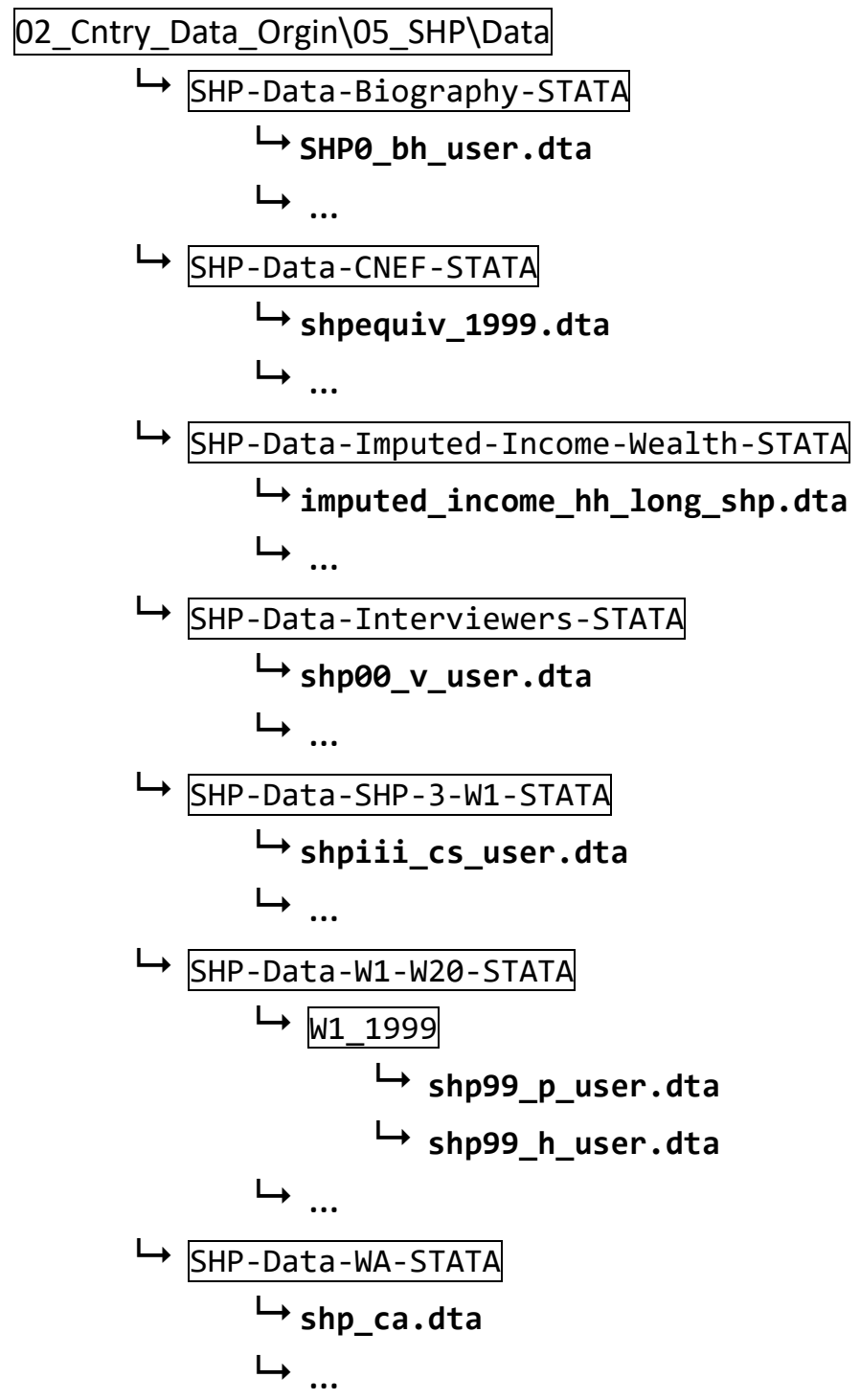

The number of waves in the folder name SHP-Data-W1-W20-STATA is accounted for automatically after filling it in in the syntax 2_CPF_Main_Fill_and_run.do in \#3. Be aware, however, of any future changes in folder names. 


\section{6_SOEP - Germany}

Data are available via the Research Data Center SOEP after granting access:

www.diw.de/en/diw 02.c.242211.en/criteria fdz soep.html

Data should be unpacked into Data keeping additionally the wave-specific subfolder (e.g. soep.v35), which contains then all the SOEP files.

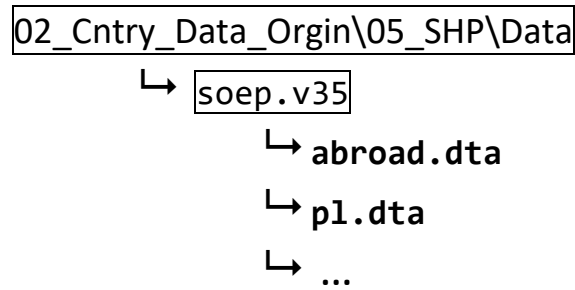

The wave-specific subfolder name is accounted for automatically after filling in the number of waves in the syntax 2_CPF_Main_Fill_and_run.do in \#3.

\section{7_UKHLS - UK}

Data are available via the UK Data Service after granting access: www.ukdataservice.ac.uk.

Data should be unpacked into Data with keeping additionally the specific subfolders' path (e.g. UKDA6614-stata\stata\stata11_se), which contains then all the wave-specific folders. These folders (e.g. bhps_w1, ukhls_w1) contain the data files for each wave.

The specific path may change from wave to wave and has to be properly included in syntax

2_CPF_Main_Fill_and_run.do in \#4, e.g.:

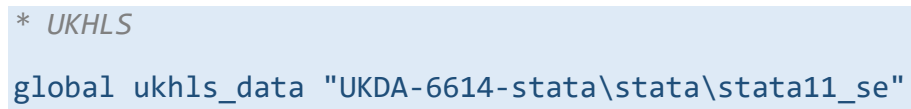

The structure should look like following:

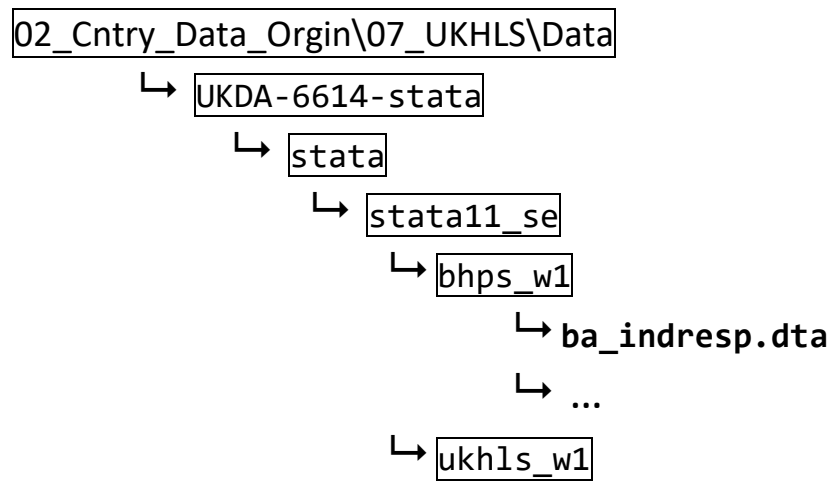




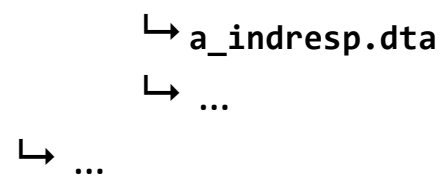

Survey-specific details

This part presents additional details and instruction for the lower-level (survey-specific) codes.

01_HILDA - Australia

1. au_01_Prepare_data- to prepare data

a. Step 1: Rename datasets

b. Step 2: Append waves of the original dataset

2. au_02_1_Harmonize ( $p 1$ - cnef)-code for the CNEF data file

3. au_02_2_Harmonize (p2- combined)-code for the original variables from all waves

4. au_02_3_Combine_p1p2 - combines p1 and p2 into a xx_02_CPF.dta

5. au_03_Sample_selection - sample selection

02_KLIPS - South Korea

1. ko_01_Prepare_data - to prepare data

a. Install ado renvars (for renaming)

net install http://www.stata-journal.com/software/sj5-4/dm88_1

b. Step 1: Prepare p-files

c. Step 2: Prepare h-files

d. Step 3: Combine $p \& h$ files

2. ko_02_Harmonize- to prepare harmonised variables

3. ko_03_Sample_selection-sample selection 
03_PSID - US

The philosophy behind PSID data differs from other surveys. PSID is the oldest ongoing research in the CPF set and the most challenging to incorporate. Unfortunately, unlike in other surveys, adding new waves of PSID to CPF cannot be achieved at the file-level (e.g. by updating a file name). The reason is that names of variables which refer to the same construct (e.g. age, employment status) change from wave to wave (e.g. the variable for employment status is named ER30509 in 1986, ER33111 in 1994, ER34317 in 2015, and ER34516 in 2017). Therefore, all variables must be retrieved separately from all waves by searching in PSID's online system (https://simba.isr.umich.edu). This is a challenge for users who would like to add new items or new waves to the CPF data. To add to the complexity, items are stored in separate variables for Reference Persons (called Heads in older waves) and Partners (called Spouses in older waves). Also, similar questions were sometimes framed differently for Reference Persons and Partners and included in different waves. Therefore, the syntax for PSID is more complex and requires additional clarification.

\section{1. us_01_1_Create_psid_crossy_ind}

This lower-level code is run from 2_CPF_Main... syntax to create psid_crossy_ind.dta. Note, however, that code us_01_1 uses the input code provided by PSID in the zipped file (e.g. IND2017ER) which might have to be updated with new waves. Also, the code us_01_1 refers to the individual data file at the end of the infix part, which has to be updated in the 2_CPF_Main.

\section{2. us_01_2_Create_waves_psidtools}

The psidtools implemented in this code will automatically unpack the files, prepare and copy them into PSIDtools_files (one family file per wave and one individual file). These are the base input files for the CPF dataset. After this, the zipped files in Family and Ind Files (zip) folder can be deleted.

\section{3. us_01_3_Get_vars}

When adding new variables or new waves to PSID, users must modify the us_01_3_Get_vars. It contains a combvars program which is a wrap up for psidtools command. Combvars is used to

- combine variables across waves - strings of variables related to the same item are different for each wave (e.g. age: ER30004, ER30023, etc.)

- reshape them into a long format (using psidtools)

- $\quad$ save them as separate files

- add names to global macro for further use (merging) 
The combvars program uses files created by psidtools in PSIDtools_files folder. However, names of the variables have to inserted by hand (names can be found and copied from the PSID's online search tools at https://simba.isr.umich.edu/Zips/ZipMain.aspx) into specific item-lists. For example, the code to add and combine original variables which refer to the age of respondent is:

\begin{tabular}{|c|c|c|c|c|c|}
\hline $\begin{array}{l}\text { combvars age } \\
\text { [73] ER30120 }\end{array}$ & [74]ER30141 & [75]ER30163 & [76]ER30191 & [77]ER30220 & [78]ER30249 \\
\hline [79] ER30286 & [80]ER30316 & [81]ER30346 & [82]ER30376 & [83]ER30402 & 432 \\
\hline [85] ER30466 & [86]ER30501 & [87]ER30538 & [88]ER30573 & [89]ER30609 & {$[90] \mathrm{E}$} \\
\hline [91]ER30692 & [92]ER30736 & [93]ER30809 & [94]ER33104 & [95]ER33204 & [96] \\
\hline [97]ER33404 & [99]ER33504 & [01]ER33604 & [03]ER33704 & [05]ER33804 & [07] \\
\hline 09] ER34004 & ]ER34104 & R34204 [15 & $34305[17]$ & 504") & \\
\hline
\end{tabular}

Unlike in other survey, names of variables in PSID changes from wave to wave. Thus, names must be first combined across waves. Each of the items on the list refers to a specific wave (e.g. [68] refers to wave from 1968). The last item on the list refers to the last wave (here: [17]ER34504). If new waves are to be added, users have to add an item to the list with a name of a variable in the latest wave (e.g. [19]ER...). It has to be done for all variables separately.

Thus, the syntax us_01_3 contains following steps:

- Step1: Define combvars program to be used in this syntax and run global vars'»’

- Step 2: Run combvars to combine vars across waves. This will create separate long files for each item

- Step 3: Combine single-item long files from step 2 into us_01.dta

- Step 4: Add variables which constant across all waves to us_01.dta (get them from long psid_crossy_ind.dta)

Command "Add new time-constant vars - only if necessary" can be used to add new time-constant variables once the us_01.dta is already created.

Command "Add new files - only if necessary" can be used to add a new block of items using combvars (after creating us_01.dta).

\section{4. us_02_Harmonize}

- Selecting observations - the default option is "Keep 2: heads \& partners". The current version of CPF is not adjusted to include other family members. However, users may choose different sets of observations if necessary. 
- For ISCO variables, the code refers to external do-files (due to their length they are stored separately). Note that ISCO recoding can take a lot of time.

5. us_03_Sample_selection

In the default option, it keeps spouses and partners only (Keep 2), repeating the code in 02.

04_RLMS - Russia

1. ru_01_Prepare_data- to prepare data

- Combine individual and household files (which are already combining waves in a long format)

2. ru_02_Harmonize- to prepare harmonised variables

3. ru_03_Sample_selection - sample selection

05_SHP - Switzerland

1. ch_01_1_Prepare_data_Equiv_to_long- to prepare supplementary CNEF variables

2. ch_01_2_Prepare_data_Waves_to_long-to prepare individual data

This is also a place for adding new variables

- there are 3-4 places you have to put the name of a new variable from the wave-specific files you want to add

- these places are indicated as:

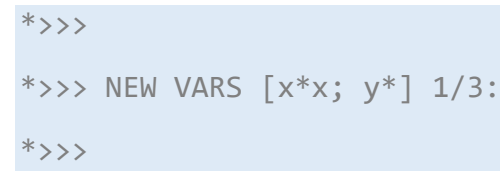

- you must adjust the formatting of the name in each case

- $\quad x^{*} x$ - variables with year inside of the name, e.g. p17e50 (3 places to add)

- $y^{*}$ - variables with the year at the end of the name, e.g. educat17 (4 places to add)

- $\quad$ lease, verify if the results are correct, there are a few rules which help to check it

3. ch_02_1_Harmonize_(p1- equiv)- to prepare supplementary variables from CNEF

4. ch_02_2_Harmonize_( 2 2-waves $)$ - to prepare the main variables 
5. ch_02_3_Combine_p1p2-combine the main file with CNEF variables. Additionally, some missing values are cross-filed.

6. ru_03_Sample_selection-sample selection

06_SOEP-Germany

1. ge_01_Prep_data- to prepare data

This is a place for adding new raw variables from the original SOEP datafiles. Users must identify the specific original data file and variables and add the name(s) in an appropriate place in the syntax. For example, if variable newvar comes from SOEP's health.dta, the original name of a variable must be added to the KEEP command under the headline *\# health.dta \#., e.g.:

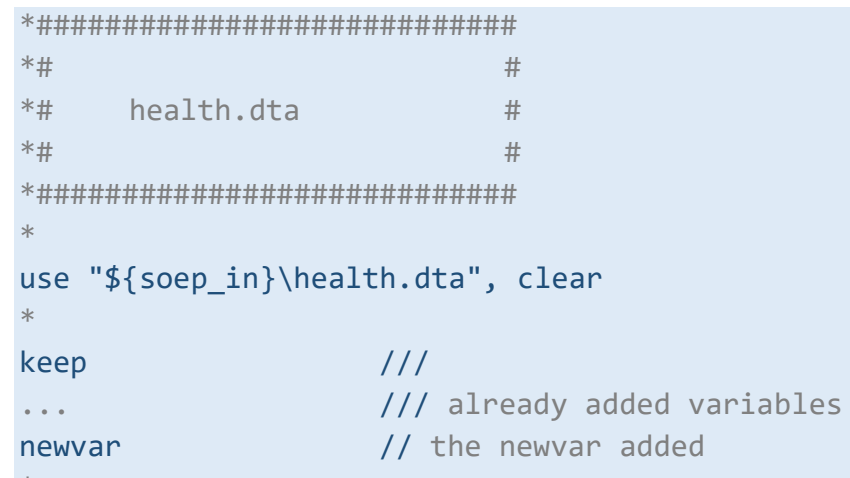

In case when the original data file is not listed in the syntax, it can be added in a similar way as the other files. First, open the new datafile, keep variables, and save the file under new name:

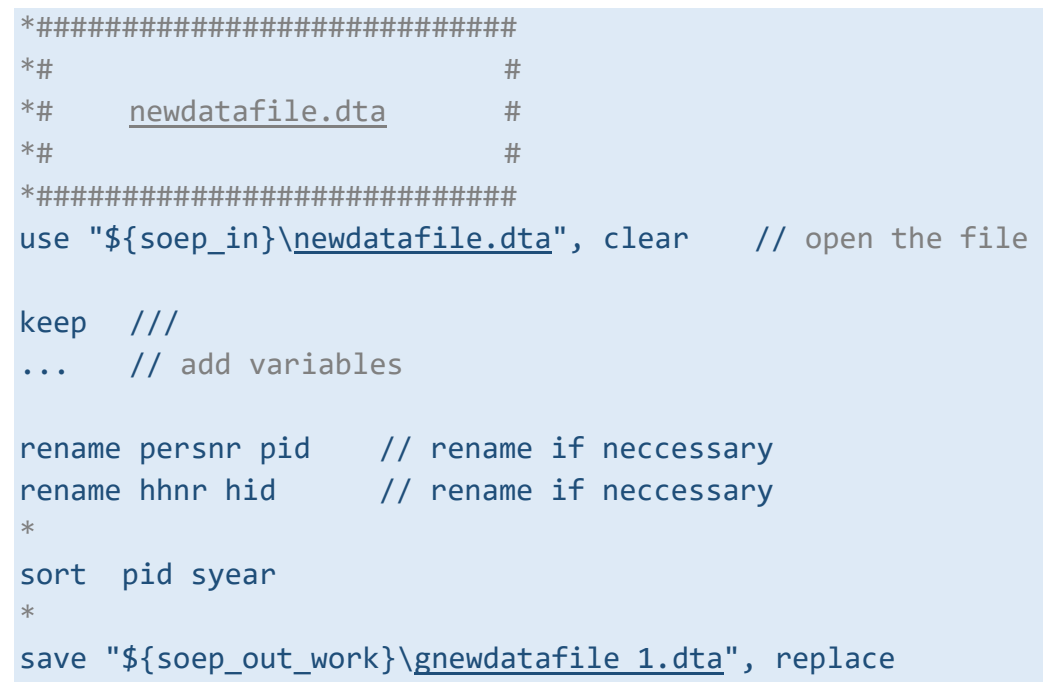


Then, add the new file to the final merge command, e.g.:

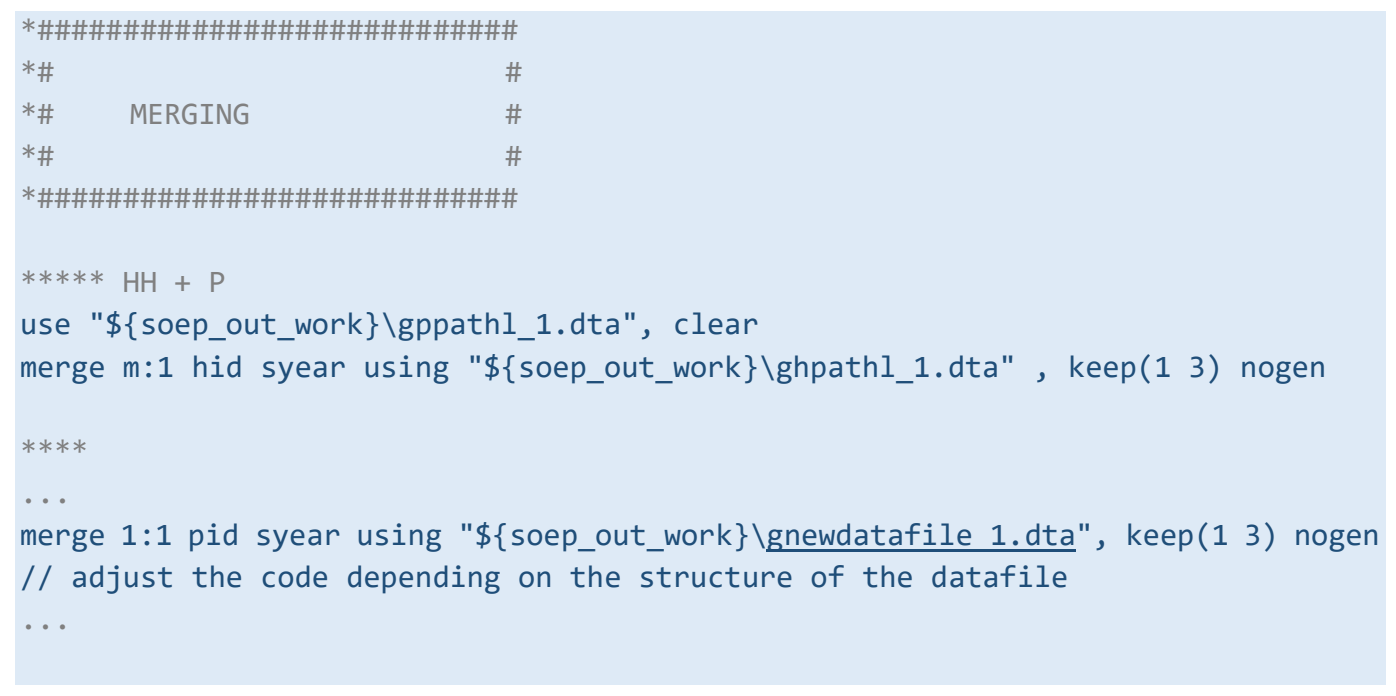

2. ge_02_Harmonize - to prepare harmonised variables

3. ge_03_Sample_selection - sample selection

07_UKHLS - UK

1. uk_01_Prepare_data-to prepare data

- The code combines BHPS and UKHLS datasets

- Note that operations require much disk space. Therefore, temporary files are deleted

- Also, the combined file is large. For this reason, one of the last procedures in the syntax is DROP to delete variables which will not be used in further harmonisation.

Users might have to adjust the command when adding new variables. Additionally, if the order of the variables changes with new editions, the DROP command must be modified (or deleted).

2. uk_02_Harmonize- to prepare harmonised variables

- waves from BHPS and UKHLS have mostly separate sets of variables

3. uk_03_Sample_selection - sample selection 


\section{Doing analysis with the CPF}

To account for the hierarchical data structure, users can refer to the following variables:

- country - to identify countries (surveys)

- $\quad$ id - to uniquely identify respondents (based the original id number from source surveys)

- wave, wavey, or intyear - to include the time dimension:

0 wave - country-specific wave number (counting from 1)

0 wavey - the main (initial) year of data collection for a given wave

○ intyear - year of interview

There are different approaches to account for the entire 3-level hierarchical structure. For example, users can include countries as dummies, perform contextual analysis, run the separate analysis by country, or use robust (clustered) standard errors. Performing a multilevel model with all 3-levels is problematic due to the low number of countries (however, Bayesian approach can be considered in this case). For more information on multilevel and panel analysis, we recommend popular statistical handbooks:

- Gelman A., J. Hill (2007) “Data Analysis Using Regression And Multilevel/Hierarchical Models”, New York: Cambridge University Press

- $\quad$ Snijders, T., R. Bosker (1999) “Multilevel Analysis: An introduction to basic and advanced multilevel modeling", London: Sage.

- Raudenbush, S.W., A.S. Bryk (2002) "Hierarchical Linear Models: Applications and Data Analysis Methods", Thousand Oaks, CA: Sage Publications

- Joop Hox $(2002,2010)$ "Multilevel Analysis: Techniques and Applications", Routledge

- Hoffman L., (2015) “Longitudinal Analysis: Modeling Within-Person Fluctuation and Change", Routledge

- Singer J., J. Willett (2003) "Applied Longitudinal Data Analysis: Modeling Change and Event Occurrence", Oxford University Press

- Rabe-Hesketh S., A. Skrondal (2012) “Multilevel and Longitudinal Modeling Using Stata (3rd Edition)”, Stata

- McElreath (2020). "Statistical Rethinking: A Bayesian Course (2 ${ }^{\text {nd }}$ Edition)", CRC Press

- Kruschke (2014) “Doing Bayesian Data Analysis: A Tutorial Introduction with R", Academic Press

For example, in Stata a simple regression model which accounts only for the country clustering by including a country-dummy can be written as:

reg satlife5 i.edu3 i.country

A panel model which accounts additionally for repeated observations (2-level model) can be written with the mixed command as:

mixed satlife5 i.edu3 i.country || pid:, 
After defining a panel structure with xtset, a similar model can be written with the xt-command:

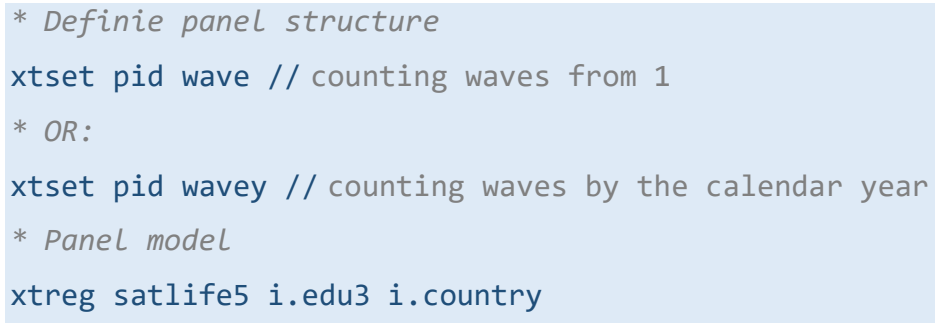

General recommendations:

- Before any substantial analysis, consider the missing values (MV) in the used variables. In most cases, MV should be removed from the analysis, e.g. by recoding them into system-missing values (.), of applying mvdecode command.

- Given that the CPF data (in version 1.0) contains more than 2.5 million observations, complex statistical analysis can be running slowly. In such a case, run the initial analysis on subsamples. Alternatively, consider other statistical software, such as Mplus or R (especially for Bayesian analysis).

- Be aware of different time frames and differences in gaps between years of data collection (e.g. in PSID) when performing longitudinal analysis. Depending on the research question and method, consider using wave, wavey or intyear. 


\section{Open-science platform for CPF}

\section{Tools and services}

CPF is an open-science project, which means that it provides access to all resources, including the programming code. Furthermore, the code can be improved and developed by anyone who wishes to contribute to the project. To allow the open access and community-based development, we have built an open-science platform that connects several tools: website, online Forum, GitHub and OSF (Figure 9).

Figure 9. The structure and tools of the CPF's open-science framework

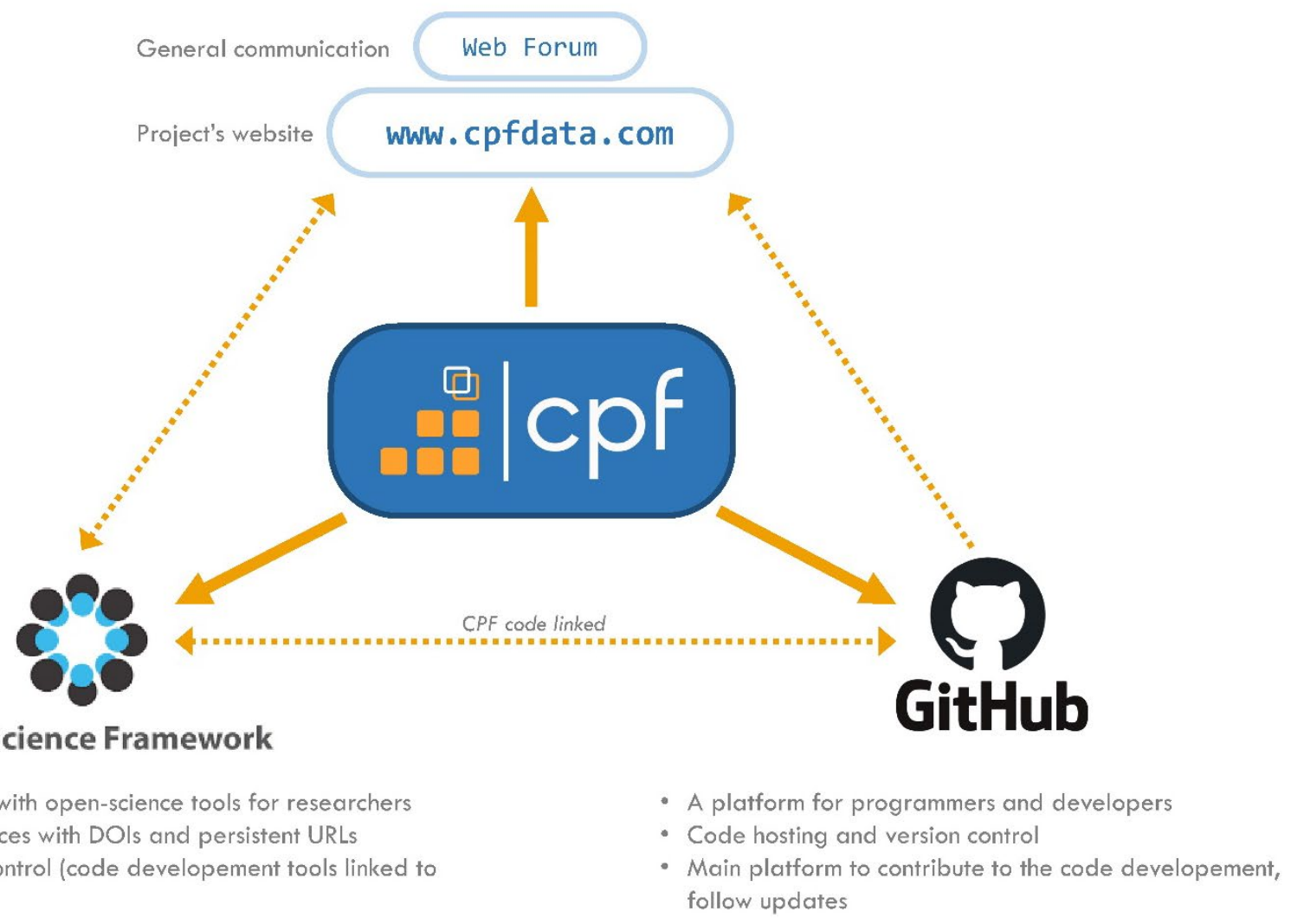

The central element is the project's website ( $\underline{w w w . c p f d a t a . c o m})$ that contains all important information, documentation and the latest major version of the code. The website also includes an online forum. The Forum serves general communication, discussions and suggestions related to the code. It may also be used for asking questions and providing answers.

GitHub (www.github.com) is precisely oriented at the development of the CPF code. GitHub is a code hosting platform for collaborations in code development, especially useful for managing open-source 
projects. It allows users to access the main and alternative versions of the code, share their modifications, track changes and continuously integrate them into consecutive versions. Extensions, improvements or alternative versions of the code can be offered by all researchers and programmers who register free of charge at the GitHub platform. Importantly, all changes are recorded, providing version control functionality.

Open Science Framework (OSF; www.osf.io) is one of the most popular open-science platforms, which facilitates open collaboration in research. OSF integrates many tools and services which support managing, organising, documenting and sharing all aspects of a project. Among others, OSF allows preregistering studies, storing code and data; it is linked to preprint services and many scientific platforms. It facilitates collaborative workflow on projects, allows to document the work and progress. Similarly to GitHub, OSF uses a version control system, so all changes to the project are recorded. OSF allows additionally to register the project at each stage and creates an archival version of the project with a unique hyperlink. All materials can be registered this way, receiving permanent links and DOIs. Importantly, OSF includes a GitHub add-on which directly links files stored at GitHub repository into the OSF project. This way, changes to the code can be introduced either through GitHub or OSF, and they are synchronised so that the code at the OSF is always up to date.

Links to the resources:

- Website: $\underline{w w w . c p f d a t a . c o m}$

- Forum: www.cpfdata.com/forum

- GitHub: www.github.com/cpfdata

- OSF: $\underline{\text { www.osf.io/h3yxq }}$

\section{Help and support}

The up-to-date documentation of CPF can always be found at the projects' website: http://www.cpfdata.com/download. Questions regarding the CPF code can be asked on the Forum or by email contact@cpfdata.com. CPF is an independent project developed on a voluntary basis. As such, it does not engage employees responsible for support and help. The CPF team will try to answer all the questions, but extensive support cannot always be provided. 


\section{Contribution and cooperation}

User's improvements and suggestions will be recorded, incorporated and shared using open online platforms (i.e. web forum and GitHub code repository) to allow continuous development and regular updates to the official versions of the code.

CPF is an open and ongoing project. We invite interested users to provide feedback (e.g. on the Forum) or contribute to the development of the code (through GitHub or OSF). We are also happy to cooperate in research or support the development of the research network by linking people and institutions. Do not hesitate to contact us! 


\section{References}

Allanson, P. F. (2011). On the characterisation and economic evaluation of income mobility as a process of distributional change. The Journal of Economic Inequality, 10(4), 505-528. doi:10.1007/s10888-011-9172-5

Büchel, F., \& Frick, J. R. (2004). Immigrants in the UK and in West Germany ?Relative income position, income portfolio, and redistribution effects. Population Economics, 17(3). doi:10.1007/s00148004-0183-4

Buck, N., \& McFall, S. (2012). Understanding Society: design overview. Longitudinal and Life Course Studies, 3, 5-17.

Burkhauser, R. V., Butrica, B. A., Daly, M. C., \& Lillard, D. R. (2001). The Cross-National Equivalent File: A product of cross-national research. In I. Becker, N. Ott, \& G. Rolf (Eds.), Social Insurance in a Dynamic Society. Frankfurt: Campus Fachbuch.

Chen, W.-H. (2009). Cross-National Differences in Income Mobility: Evidence from Canada, the United States, Great Britain and Germany. Review of Income and Wealth, 55(1), 75-100. doi:10.1111/j.1475-4991.2008.00307.x

Cho, J., \& Lee, A. (2013). Life Satisfaction of the Aged in the Retirement Process: A Comparative Study of South Korea with Germany and Switzerland. Applied Research in Quality of Life, 9(2), 179-195. doi:10.1007/s11482-013-9237-7

Cooke, T. J., Boyle, P., Couch, K., \& Feijten, P. (2009). A longitudinal analysis of family migration and the gender gap in earnings in the united states and great britain. Demography, 46(1), 147-167.

DiPrete, T. A., \& McManus, P. (1996). Institutions, Technical Change, and Diverging Life Chances: Earnings Mobility in the United States and Germany. American Journal of Sociology, 102(1), 3479.

Dubrow, J. K., \& Tomescu-Dubrow, I. (2015). The rise of cross-national survey data harmonisation in the social sciences: emergence of an interdisciplinary methodological field. Quality \& Quantity, 50(4), 1449-1467. doi:10.1007/s11135-015-0215-z

Ehlert, M. (2013). Job loss among rich and poor in the United States and Germany: Who loses more income? Research in Social Stratification and Mobility, 32, 85-103. doi:10.1016/j.rssm.2012.11.001

Frick, J. R., Jenkins, S. P., Lillard, D. R., Lipps, O., \& Wooden, M. (2007). The Cross-National Equivalent File (CNEF) and Its Member Country Household Panel Studies. Schmollers Jahrbuch : Zeitschrift für Wirtschafts- und Sozialwissenschaften, 127, 627-654.

Gerry, C. J., \& Papadopoulos, G. (2015). Sample attrition in the RLMS, 2001-10. Economics of Transition, 23(2), 425-468. doi:10.1111/ecot.12063

Giesselmann, M., Bohmann, S., Goebel, J., Krause, P., Liebau, E., Richter, D., . . . Liebig, S. (2019). The Individual in Context(s): Research Potentials of the Socio-Economic Panel Study (SOEP) in Sociology. European Sociological Review, 35(5), 738-755. doi:10.1093/esr/jcz029

Goebel, J., Grabka, M. M., Liebig, S., Kroh, M., Richter, D., Schröder, C., \& Schupp, J. (2019). The German Socio-Economic Panel (SOEP). Journal of Economics and Statistics, 239(2), 345-360. doi:10.1515/jbnst-2018-0022

Johnson, D., McGonagle, K., Freedman, V., \& Sastry, N. (2018). Fifty Years of the Panel Study of Income Dynamics: Past, Present, and Future. Ann Am Acad Pol Soc Sci, 680(1), 9-28.

doi:10.1177/0002716218809363 
Kaminska, O., \& Lynn, P. (2017). Survey-Based Cross-Country Comparisons Where Countries Vary in Sample Design: Issues and Solutions. Journal of Official Statistics, 33(1), 123-136. doi:10.1515/jos-2017-0007

Kozyreva, P., \& Sabirianova Peter, K. (2015). Economic change in Russia: Twenty years of the Russian Longitudinal Monitoring Survey. Economics of Transition, 23(2), 293-298. doi:10.1111/ecot.12071

McCall, L., \& Percheski, C. (2010). Income Inequality: New Trends and Research Directions. Annual Review of Sociology, 36(1), 329-347. doi:10.1146/annurev.soc.012809.102541

McGonagle, K. A., Schoeni, R. F., Sastry, N., \& Freedman, V. A. (2012). The Panel Study of Income Dynamics: Overview, Recent Innovations, and Potential for Life Course Research. Longitudinal and Life Course Studies, 3(2), 268 - 284.

McManus, P. A. (2003). Parents, Partners, and Credentials: Self-Employment Mobility in the United States and Germany. In Inequality Across Societies: Familes, Schools and Persisting Stratification (pp. 171-200).

Musick, K., Bea, M. D., \& Gonalons-Pons, P. (2020). His and Her Earnings Following Parenthood in the United States, Germany, and the United Kingdom. American Sociological Review, 85(4), 639-674. doi:10.1177/0003122420934430

Platt, L., Knies, G., Luthra, R., Nandi, A., \& Benzeval, M. (2020). Understanding Society at 10 Years. European Sociological Review. doi:10.1093/esr/jcaa031

Revilla, M. A., Saris, W. E., \& Krosnick, J. A. (2014). Choosing the Number of Categories in Agree-Disagree Scales. Sociological Methods \& Research, 43(1), 73-97. doi:10.1177/0049124113509605

Rose, D. (1995). Household panel studies: An overview. Innovation: The European Journal of Social Science Research, 8(1), 7-24. doi:10.1080/13511610.1995.9968428

Siegers, R., Belcheva, V., \& Silbermann, T. (2020). SOEPcore v35 - documentation of sample sizes and panel attrition in the German Socio-Economic Panel (SOEP) (1984 until 2018): DIW/SOEP: SOEP Survey Papers, 826.

Slomczynski, K. M., \& Tomescu-Dubrow, I. (2019). Basic Principles of Survey Data Recycling. In T. P. Johnson, B.-E. Pennell, I. A. L. Stoop, \& B. Dorer (Eds.), Advances in Comparative Survey Methods: Multinational, Multiregional, and Multicultural Contexts (3MC), : John Wiley \& Sons.

Watson, N., \& Wooden, M. (2020). The Household, Income and Labour Dynamics in Australia (HILDA) Survey. Journal of Economics and Statistics, O(0). doi:10.1515/jbnst-2020-0029

Wolf, C., Joye, D., Smith, T., \& Fu, Y.-c. (2017). Harmonising Survey Questions Between Cultures and Over Time. In C. Wolf, Y.-c. Fu, D. Joye, \& T. Smith (Eds.), The SAGE Handbook of Survey Methodology. London: SAGE Publications. 